\title{
Materials Prices and Productivity
}

\author{
Enghin Atalay *
}

March 22, 2013

\begin{abstract}
There is substantial within-industry variation in the prices that plants pay for their material inputs. Using plant-level data from the U.S. Census Bureau, I explore the consequences and sources of this variation in materials prices. For a sample of industries with relatively homogeneous products, the standard deviation of plant-level productivity would be $7 \%$ smaller if all plants faced the same materials prices. Moreover, plant-level materials prices are persistent, spatially correlated, and positively associated with the probability of exit. The contribution of entry and exit to aggregate productivity growth is smaller for productivity measures that are purged of materials price variation. After documenting these patterns, I discuss three potential sources of materials price variation: geography, differences in suppliers' marginal costs, and within-supplier markup differences. Together, these variables explain $15 \%$ of the variation of materials prices.
\end{abstract}

\section{Introduction}

There is substantial within-industry variation in the prices that establishments pay for their material inputs, even in industries that use and produce homogeneous inputs and outputs. This paper assesses the implications and sources of this variation in materials prices. When input prices differ across plants, plants may have lower marginal costs not only because they are able to produce more efficiently, but also because they are able to purchase intermediate inputs at relatively low prices.

${ }^{*}$ I thank Frank Limehouse and Arnie Reznek, for help with the data disclosure process. In addition, I am indebted to Aditya Bhave, Thomas Chaney, Ali Hortaçsu, Sam Kortum, Ezra Oberfield, Marshall Steinbaum, Nancy Stokey, Chad Syverson, Kirk White, Stephane Wolton, Fabrizio Zilibotti, and five anonymous referees for their helpful comments on earlier drafts. Disclaimer: Any opinions and conclusions expressed herein are those of the author and do not necessarily represent the views of the U.S. Census Bureau. All results have been reviewed to ensure that no confidential information is disclosed. 
Accounting for the variation in materials prices ${ }^{1}$ provides new answers to two longstanding questions: First, why are within-industry differences in plants' measured productivities so large? Second, what is the role of reallocation - via the entry of relatively productive plants and the exit of unproductive plants - on industry productivity growth?

Large, persistent, within-industry productivity differences are ubiquitous. Syverson (2004a), for example, estimates that, in the average 4-digit manufacturing industry, the 90th percentile plant has a total factor productivity that is approximately $90 \%$ higher than the 10th percentile plant. Given the importance that a plant's productivity has for its growth and survival, as well as the strong relationship between countries' GDPs and the average productivities of their firms, several papers have tried to explain why some plants are productive while others are not. This literature has argued that relatively productive plants are more likely to: employ high-quality inputs ( Fox and Smeets 2011), patent (Balasubramanian and Sivadasan 2011), enter export or import markets (Bernard and Jensen 1999; Eslava et al. 2004, 2013), and follow best-practice management techniques (Bloom and Van Reenen 2010). In addition, productivity dispersion is larger in markets with less intense competition (Syverson 2004b) and in countries with larger factor misallocations (Hsieh and Klenow 2009).

In the cited studies, plants' productivities are calculated as the ratio of outputs to inputs. Usually, data on input and output prices are not collected, meaning thatin most cases - real revenues are the measure of establishment outputs, while real input expenditures are the measure of establishment inputs. ${ }^{2}$ With these productivity measures, an establishment's measured productivity will depend on conditions in output and factor markets. Potentially, an establishment's measured productivity could have no relationship with how efficient it is in transforming inputs into outputs.

The potential confounding effects of input and output price variation in productivity estimation are already well known. Both Katayama, Lu, and Tybout (2009) and Gorodnichenko (2010) argue, in detail, why plant-level measured productivities may have little to do with plants' technical efficiencies. These papers propose structural estimators of estab-

\footnotetext{
${ }^{1}$ Throughout this paper, I will use the terms "intermediate inputs" and "materials" interchangeably.

${ }^{2}$ Four partial exceptions are Syverson (2004b), Eslava et al. (2004, 2013), and Ornaghi (2006). Syverson (2004b) utilizes establishment-level output price data, but does not use establishment-level intermediate input price data. Ornaghi (2006), on the other hand, has data on materials prices. His analysis focuses on the estimation of input elasticities, instead of the distribution of plant-level productivities, which is the focus here. Perhaps closest to the current paper, Eslava et al. (2004, 2013) use plant-level input and output price data from Colombia to test the hypothesis that a trade liberalization stiffens the competitive environment, forces low productivity plants to exit, and thus increases aggregate productivity.

Among these papers, only Syverson (2004b) restricts the sample to homogeneous-output industries. So, some of the variation in quantity total factor productivity in Eslava et al. (2004, 2013) will be a result of differences in output or input quality.
} 
lishments' cost and revenue functions, exploiting information derived from the solutions to their cost minimization and/or profit maximization problems. Quantifying the extent to which input price variation confounds the measurement of plants' technical efficiencies is one of the main contributions of my paper.

A second long-standing question - previously addressed in Baily, Hulten, and Campbell (1992), Griliches and Regev (1995), Foster, Haltiwanger, and Krizan (2001), and Foster, Haltiwanger, and Syverson (2008) — concerns the extent to which industry productivity growth is driven by the intra-industry reallocation of factors towards more efficient producers. Foster, Haltiwanger, and Syverson (2008) carefully argue that (conventional) revenue-based productivity measures understate the importance of reallocation and firm turnover to industry productivity growth: Since entrants charge exceptionally low prices, measures that embody output price differences will understate entrants' productivity advantages. In Foster, Haltiwanger, and Syverson (2008), as well as other papers that study reallocation and industry productivity growth, all plants in an industry are assumed to pay the same prices for their intermediate inputs. By considering the differences - across entrants, incumbents, exiting plants, and survivors - in plants' materials prices, the current paper provides a more complete depiction of the contribution of turnover to aggregate productivity growth.

The current paper also relates to and complements Kugler and Verhoogen (2012) and Manova and Zhang (2012). In these papers, plants' input/output prices proxy for the quality of the products that the plants use and produce. Kugler and Verhoogen (2012) construct a model in which input quality and plant technical efficiency are complementary in production. As a result, the authors are able to explain the observed positive relationships between a plant's size and the prices of its inputs and outputs. Manova and Zhang (2012) document that exporters sell their products at higher prices in markets that are larger, richer, more distant, and less remote. The authors argue that exporters vary the quality of their goods across the markets to which they export. Unlike these papers, I focus on industries with insubstantial quality variation, with the goal of isolating other sources of materials price variation.

By exploiting plant-level materials price - and output price - data, I am able compare the following three productivity measures: Revenue total factor productivity (TFPR) is computed using industry-level price indices for both plants' outputs and intermediate inputs. Quantity productivity (TPFQ) again uses industry-level price indices for intermediate inputs, but relies on plant-level output prices. Finally, technical efficiency (which I denote $\Phi)$ uses both plant-level materials and output prices.

Comparisons of the three productivity measures, as provided in this paper, are of interest for the following two reasons. First, differences across the productivity measures 
highlight the relevance of different models of heterogeneous-plant industry dynamics. If dispersion in (commonly-used) revenue productivity is mostly driven by technical efficiency, models examining learning-by-doing, innovation, and management practices may be particularly relevant. However, if differences in productivity measures derive from (input or output) price dispersion, models of market structure would be more salient.

Second, the different productivity measures may be more or less germane to different applications. Under some conditions, for example, the dispersion of revenue productivity is a sufficient statistic for the welfare costs of barriers to reallocation; see Hsieh and Klenow (2009). On the other hand, the distribution of technical efficiency may better summarize how far along an industry is in the adoption of a new technology. ${ }^{3}$

In Section 2, I introduce the two plant-level datasets - the Census of Manufacturers and the Commodity Flow Survey - employed in this paper, as well as the set of industries that comprise my sample. Building off of Foster, Haltiwanger, and Syverson (2008), I restrict my sample to the few industries - such as gasoline, ready-mix concrete, and corrugated boxesfor which plants' output prices and materials prices can be computed and meaningfully compared across establishments, and for which prices do not primarily reflect differences in input or output quality.

Price variation in factor and output markets is substantial, even in industries that produce commodity-like products. In the benchmark sample, the within product-year standard deviation of the logarithm materials prices is $12 \%$. I establish in Section 3.1 that TFPQ is negatively related to materials prices: the correlation between the logarithm of $T F P Q$ and materials prices is $-37 \%$. In Section 3.2, I compute the fraction of TFPQ dispersion that is due to differences in materials prices: the standard deviation would be $7 \%$ lower, and the $75 / 25$ ratio would be $10 \%$ lower, in a counterfactual world in which all plants face the same materials prices. To give context, $7 \%$ to $10 \%$ is larger than the fraction of productivity dispersion explained by the competitive environment (Syverson 2004b), and at least as large as the fraction explained by differences in labor quality ( Fox and Smeets 2011).

As I demonstrate in Sections 3.3 and 3.4, plant-level intermediate input prices are persistent, spatially correlated, and related to the probability of exit from the industry. The 1-year autocorrelation of the logarithm of plants' materials prices is $80 \%$, comparable to the autocorrelation of the logarithms of TFPR, TFPQ, or output prices. In addition, intermediate input prices are $1.4 \%$ higher for plants that are about to exit. Following from the negative correlations between quantity productivity and input/output prices, the productivity advantage of surviving plants (compared to exiting plants) is highest when using TPFQ,

\footnotetext{
${ }^{3}$ To give an example, Collard-Wexler and De Locker (2013) examine the distribution of technical efficiency in their chronicle of minimills' displacement of vertically integrated producers in the U.S. steel industry.
} 
and lower when using either TFPR or $\Phi$, as the productivity measure. Concomitantly, the contribution of net entry to aggregate productivity growth is smaller for productivity measures that embody plants' output prices (i.e., $T F P R$, but not $T F P Q$ or $\Phi$ ), but larger for productivity measures that embody input prices (i.e., TFPR and TFPQ, but not $\Phi$ ).

In Section 4, I offer three potential explanations for within-industry differences in materials prices. First, plants in particular geographic regions enjoy particularly low input prices due, for example, to the abundance of primary materials with which the intermediate input is produced. Second, plants pay relatively little for their intermediate inputs when their suppliers are exceptionally productive: productive upstream plants pass some of their low marginal costs through to their buyers. Also, even after accounting for transportation costs, suppliers tend to charge different prices for their outputs across different destinations. These within-supplier differences are a third source of price variation in intermediate goods markets. For a pooled sample of ready-mix concrete and corrugated box manufacturers, these three sources reduce the unexplained materials price variation by $15 \%$. Both the across-supplier component (i.e., low marginal cost suppliers charge, on average, low prices) and the within-supplier component (i.e., a given supplier charges different prices to different downstream plants) are important factors for explaining the variation in materials prices.

Section 5 concludes. Two robustness checks, discussing the potential confounding effects of output quality variation (Appendix A.1) and input quality variation (Appendix A.2) are included in the appendix. Additional robustness checks (Web Appendices A.3A.13), a more detailed description of the construction of the sample (Web Appendix B), and bootstrapped confidence intervals (Web Appendix C) can be found in a Web Appendix.

\section{Data and Definitions}

The purpose of this section is to introduce the data sources, data sample, and price and productivity measures that will be used in the remainder of the paper. I describe the Census of Manufacturers and the Commodity Flow Survey in Section 2.1, and then the benchmark sample in Section 2.2. I define plants' materials prices, output prices, and productivities in Sections 2.3-2.4, and finally, in Section 2.5, I briefly discuss the relationships among these price and productivity measures.

\subsection{Data Sources}

The main data sources are the Commodity Flow Survey and the Census of Manufacturers, both of which are collected and maintained by the U.S. Census Bureau. 
The Census of Manufacturers contains information on manufacturing establishments' productive characteristics: employment of production and nonproduction workers, measured in hours; the book value of building and machine capital; and expenditures on electricity. Of particular importance for the current paper, for certain industries, establishments with five or more employees list both the quantity and the value of each of the products they produce (at the 7-digit level), and the quantity and value of each of the materials they consume (at the 6-digit level). ${ }^{4}$ The Census of Manufacturers is conducted every five years, in years ending in '2' or ' 7 '. For this paper, I use the Census of Manufacturers from 1972 to 1997.

The Commodity Flow Survey allows me to impute buyer-supplier relationships, as I do in Section 4.1. Like the Census of Manufacturers, the Commodity Flow Survey is conducted every five years, in years ending in ' 2 ' or ' 7 ', although it did not begin until 1993. Surveyed establishments are asked to list 20-40 shipments that they make each quarter. ${ }^{5}$ Each observation includes information on: the weight and value of the shipment; a five-digit code, specifying the commodity that was shipped; the method of transport (air, truck, rail, courier service, etc.); the destination zip code ${ }^{6}$ and the identity of the sending establishment. Unfortunately, the identity of the receiving establishment is not recorded, meaning that buyers and suppliers cannot be linked directly; I describe, in Section 4.1, the algorithm used to impute the buyer of each shipment. In Section 4, I employ the 1993 and 1997 Commodity Flow Surveys.

\subsection{Sample}

Similar to Roberts and Supina (1996, 2000) and Foster, Haltiwanger, and Syverson (2008), the analysis centers around industries for which outputs and inputs are relatively homogeneous. In industries with heterogeneous inputs or outputs, differences in quality may be a primary source of the variation in the prices that different firms charge. I would like, as much as possible, to rule out quality as a source of input or output price variation. An additional restriction is that both the inputs and outputs should be measured in units that are comparable across establishments. ${ }^{7}$

\footnotetext{
${ }^{4}$ To give the reader an idea of the scope of a 7 -digit product, ready-mix concrete (3273000) is one of the larger product groups, while one of the smaller product groups is self-rising family white flour (2044126). For 1992, http://www.census.gov/prod/2/manmin/mc92-r-1.pdf contains a description of the product codes.

${ }^{5}$ In 1993, approximately 60 thousand (out of the 350 thousand existing manufacturing plants) were surveyed in the Commodity Flow Survey, while, in 1997, approximately 30 thousand plants were surveyed.

${ }^{6}$ There are roughly 45 thousand zip codes in the United States, meaning that the average zip code contains approximately 8 manufacturing plants.

${ }^{7}$ This second restriction rules out industries like oak, hardwood rough lumber (7-digit product code $=$ 2421163). For this industry, output is measured in units of board feet, but different plants manufacture lumber with different thickness. For this reason, it is difficult to compare different plants' output prices, productivities, or other plant-level characteristics.
} 


\begin{tabular}{lccc}
\hline \multicolumn{1}{c}{ Sample } & Units of Output & Material Inputs & $N$ \\
\hline Boxes, Year $\leq 1987$ & Short Tons & Paper/Paperboard (90\%) & 1820 \\
\hline Boxes, Year $\geq 1992$ & Square Feet & Paper/Paperboard (89\%) & 646 \\
\hline Ground Coffee & 1000 Pounds & Green Coffee Beans (80\%) & 300 \\
\hline Ready-Mix Concrete & 1000 Cubic Yards & $\begin{array}{c}\text { Cement (53\%) } \\
\text { Sand/Gravel (28\%) }\end{array}$ & 3708 \\
\hline White Wheat Flour & 50-Pound Sacks & Wheat (90\%) & 503 \\
\hline Gasoline & 1000 Barrels & Crude Petroleum (84\%) & 692 \\
\hline Milk, Bulk & 1000 Pounds & $\begin{array}{l}\text { Unprocessed } \\
\text { Whole Milk (88\%) }\end{array}$ & \multirow{2}{*}{127} \\
\hline Milk, Packaged & 1000 Quarts & $\begin{array}{l}\text { Unprocessed } \\
\text { Whole Milk (72\%) }\end{array}$ & 2099 \\
\hline Raw Cane Sugar & Short Tons & Sugar Cane (93\%) & 177 \\
\hline Carded Cotton Yarn & 1000 Pounds & $\begin{array}{l}\text { Cotton Fibers (80\%), } \\
\text { Polyester Tow (10\%) }\end{array}$ & 431 \\
\hline Pooled & - & - & 10,503 \\
\hline
\end{tabular}

Table 1: Description of the 10 industries in the benchmark sample.

Notes: The percentages that appear in the Material Inputs column are the fraction of materials expenditures that go to each particular material input. The Material Inputs column shows the inputs that represent greater than $6 \%$ of the average plant's total material purchases.

The 10 industries (alternatively referred to as "products") that comprise the main sample are corrugated boxes (with the years 1972-1987 and 1992-1997 analyzed separately), ground coffee, ready-mix concrete, white wheat flour, gasoline, bulk milk, packaged milk, raw cane sugar, and carded cotton yarn; see Table $1 .^{8,9}$ Approximately one-third of the 10,503 plant-year observations are from plants that manufacture ready-mix concrete. However, when observations are weighed by their real revenues, the gasoline industry is the most prominent: Approximately three-quarters of the total revenues are earned by plants from this industry.

To be in the benchmark sample, the manufacturers must also fill out the materials and production supplements. These supplemental forms, which the Census sends out to larger establishments, are necessary to compute the unit values of manufacturers' outputs and materials purchases.

\footnotetext{
${ }^{8}$ A problem similar to the one described in footnote 7 exists for the post-1992 corrugated box industry. Beginning in 1992, the units of output switch from thousands of pounds to thousands of square feet. I detail my response to this potential problem in Web Appendix B.1.

${ }^{9}$ Corrugated boxes, raw cane sugar, gasoline, ground coffee, and ready-mix concrete are included in both the current paper and Foster, Haltiwanger, and Syverson (2008). I could not include carbon black, block ice, or processed ice, as there were insufficiently many plants that filled out both the production and materials supplements. I do not include hardwood flooring or plywood, the last two industries that Foster, Haltiwanger, and Syverson (2008) include. Large output price dispersions seem to indicate that the outputs of these industries are not sufficiently homogeneous.
} 
Thus, there are two sources of sample selection. First, I have chosen industries based on the characteristics of the outputs produced and inputs purchased. These industries tend to use materials particularly intensely. Since the scope for price differences to cause measured productivity dispersion increases with the intensity of intermediate input usage (see Equation 8), it is likely that the decline in total factor productivity dispersion is larger for the 10 industries in my sample than for the broader manufacturing sector.

Second, the plants in the benchmark sample tend to be larger, relative to the other plants from their respective industries. The average plant in my sample employs roughly five times more employees and has revenues that are four times larger than the average plant in their respective industry. (For more details, see Web Appendix B.1.) Since the probability of exit tends to decrease with size, the plants in my benchmark sample are relatively more likely to survive: Plants in the benchmark sample have a 5-year survival rate of $86 \%$, compared to the average survival rate for plants in their corresponding 4-digit Standard Industrial Classification (SIC) industries, $72 \%$.

These sample selection issues limit the generalizability of the results given in Sections 3 and 4. However, by sacrificing generality, I am able to isolate the effect of differences in materials prices on intra-industry productivity dispersion.

\subsection{Assumptions}

I make five assumptions regarding plants' production technologies and the way in which intermediate inputs, labor, capital, and electricity are supplied. The aim of these assumptions is to highlight the importance of price dispersion in the measurement of plant-level productivities. Towards this goal, I will, as much as possible, adhere to conventional assumptions made in the literature on plant-level production function estimation. The key assumption that I will relax is that all plants within an industry pay the same unit price for their intermediate inputs. Relaxing this assumption potentially has a significant effect on productivity measurement, as intermediate inputs represent roughly $60 \%$ of input expenditures in the median manufacturing industry.

Assumption 1: Plants within an industry have constant-returns-to-scale Cobb-Douglas production functions, with labor, capital, electricity, and materials as the inputs. Furthermore, factor shares are common across all plants within an industry-year combination.

There are three components to the first assumption: a unitary elasticity of substitution, common factor shares within an industry, and constant returns to scale. The unitary elasticity of substitution is common in studies of plants' production functions, mainly for 
convenience. However, several authors have estimated an elasticity of substitution between labor and capital that is less than 1 (e.g., Raval 2011). For the objects of interest, the CobbDouglas assumption seems to have little effect on the dispersion of measured productivity. I show, in Web Appendix A.3, that the results of Section 3 are robust to complementarities among material inputs and other inputs.

The other parts of Assumption 1 are also rather innocuous. In Syverson (2004a), the relationships between within-industry productivity dispersion and other industry characteristics are robust to using plant-specific factor shares when estimating plants' TFPs. Related to the constant-returns-to-scale component of Assumption 1, Syverson (2004b) estimates that the returns to scale are indistinguishable from 1 for plants in the ready-mix concrete industry, the industry that contains roughly one-third of the plants in my sample. ${ }^{10}$

Assumption 2: The unit input costs of capital, labor, and electricity are the same for all plants within an industry-year combination. In addition, the unit prices of all inputs are constant in the amount purchased.

Data limitations necessitate the assumption that all plants face the same costs for a unit of capital services. The assumption that electricity costs are the same across plants within an industry can be relaxed, without changing any of the results of Section 3.11,12

Assumptions 3-5 deal with the fact that plants may produce multiple outputs and purchase multiple intermediate inputs.

Assumption 3: The fraction of each input employed in producing a particular product equals the plant's share of revenue coming from that product.

The need for Assumption 3, an assumption also made by Foster, Haltiwanger, and Syverson (2008), stems from a limitation of the dataset. In particular, for plants that produce multiple goods, it is impossible to know exactly how much of each input is used in

\footnotetext{
${ }^{10}$ Baily, Hulten, and Campbell (1992) estimate returns to scale for a broader set of industries and find the same result.

${ }^{11}$ Davis, Grim, and Haltiwanger (2008) compute plant-level energy prices and show that there is substantial variation, within industries, in the cost of a kilowatt-hour of electricity. In an unreported robustness exercise, I check that the results of Section 3 are virtually identical after relaxing the assumption that all plants face the same electricity prices, the reason being that the expenditure share of energy is small (on average, 2.5\%) for plants in the benchmark sample.

${ }^{12}$ Differences in labor quality, across plants, may muddle the interpretation of plants' productivities. Using hours worked as the measure of labor means that plants with exceptionally skilled workers would appear to be highly productive. If workers' wages reflect differences in skill (as opposed to, for example, workers' bargaining power), it would be preferable to measure labor inputs by the wages paid by each plant. In an unreported robustness check, I reproduce Tables 2 and 3 using the wage bill, instead of hours worked, as the measure of labor inputs. The results are virtually identical when using this different measure of labor inputs.
} 
the production of each output. I make the simplest possible assumption, and assume that each input is allocated in proportion to the plant's sales of each product. For example, for a hypothetical plant that employs $L$ units of labor and sells $Y_{g}$ dollars of good $g$, for $g \in\{1, \ldots G\}$, the amount of labor used in the production of $g$ is

$$
L \cdot \frac{Y_{g}}{\sum_{\hat{g}=1}^{G} Y_{\hat{g}}} .
$$

Similar to Foster, Haltiwanger, and Syverson (2008), I argue that the dispersion of productivity is robust to the way in which inputs are allocated to outputs, mainly because the plants in my sample tend to be heavily specialized in the goods they manufacture.

In addition to Assumptions 1-3, which are common in papers that estimate plantlevel productivities, I make two assumptions on the substitutability among different material inputs. Together, Assumptions 4 and 5 will allow me to compute plant-specific materials prices from the data at hand. While restrictive, they are much less so than the common presumption that all plants face the same intermediate input prices.

Assumption 4: If multiple intermediate inputs are observed, the elasticity of substitution between the materials is 0 .

This assumption is pertinent only for the two industries, plants producing ready-mix concrete or yarn, for which I observe multiple material inputs being employed. I show, in Web Appendix A.4, that the level of productivity dispersion is extremely robust to moderate levels of substitutability among the different material inputs.

Assumption 5: The elasticity of substitution, between plants' "priced" and "non-priced" materials is 1. In addition, the elasticity of substitution between "non-priced" materials and capital, labor, and electricity is also 1.

Here, "priced materials" are the materials that most plants in the industry purchase. For instance, in the case of yarn manufacturers, cotton fibers and polyester tow are the "priced materials." The non-priced materials are purchased by only a few plants in the industry. Again, turning to the yarn industry, approximately $10 \%$ of the expenditures on intermediate inputs go to purchases of materials other than cotton fibers (see the 'Material Inputs' column of Table 1). Some of these yarn-producing plants purchase silk fibers; others purchase nylon tow. Since only a few plants purchase these materials, it is difficult to ascertain if plants are purchasing these inputs relatively cheaply or expensively. I treat the "non-priced" materials as if they were any other input for which I do not observe unit prices, such as capital, and assume that there is a unitary elasticity of substitution between "non-priced" materials and "priced" materials, labor, capital, and electricity. 


\subsection{Definitions}

In this subsection, I define plants' materials and output prices, as well as the three plantlevel productivity measures: TFPQ, TFPR, and $\Phi$. The first two productivity measures are exactly as in Foster, Haltiwanger, and Syverson (2008). The productivity measure that is new to this paper, $\Phi$, aims to isolate plants' abilities to transform inputs into outputs. In particular, $\Phi$ should not reflect plants' abilities to sell their output at a relatively high price, or to purchase their intermediate inputs at a relatively low price.

I begin by defining plants' input and output prices. The price, $P_{i j t}^{\text {out }}$, that plant $i$ charges for product $j$ in year $t$ is simply the ratio of revenues, $Y_{i j t}$, to physical quantity shipped, $Q_{i j t}$ :

$$
P_{i j t}^{o u t} \equiv \frac{Y_{i j t}}{Q_{i j t}}
$$

Before defining plant-level input prices, I introduce some notation. Let $M_{i j t}$ be the expenditures on materials of plant $i$ in the production of product $j$ in year $t$. Plant $i$ 's purchases consist of "non-priced" materials, which I denote using $M_{i j t}^{0}$, and "priced" materials, which I denote using $M_{i j t}^{1}$ (and $M_{i j t}^{2}$ if $j$ is produced using two material inputs). Let, $s_{j t}^{\varkappa}$ denote the average fraction - across plants in my sample in industry $j$ and year $t$ - of materials expenditures that are spent on material $\varkappa^{13}$ Finally, let $S_{j t}$ denote the average fraction of materials expenditures, in industry $j$ and year $t$, that go to "priced" materials. ${ }^{14}$

For plants in industries that use only one type of "priced" material (i.e., all industries except for ready-mix concrete and yarn), the input price equals the ratio of materials expenditures $\left(M_{i j t}^{1}\right)$ to the physical quantity consumed $\left(N_{i j t}^{1}\right)$ of the lone priced material:

$$
P_{i j t}^{i n} \equiv \frac{M_{i j t}^{1}}{N_{i j t}^{1}}
$$

To construct plant-level materials prices for ready-mix concrete and yarn manufacturers, I begin by defining a unit of the intermediate input bundle as follows:

$$
\begin{aligned}
N_{i j t} & \equiv \min \left\{\frac{N_{i j t}^{1}}{\bar{N}_{j t}^{1}} \div\left(\frac{s_{j t}^{1}}{S_{j t}}\right), \frac{N_{i j t}^{2}}{\bar{N}_{j t}^{2}} \div\left(\frac{s_{j t}^{2}}{S_{j t}}\right)\right\} \\
& =\lim _{\varrho \rightarrow 0}\left(\left(\frac{s_{j t}^{1}}{S_{j t}}\right)^{\frac{1}{\varrho}} \cdot\left(\frac{N_{i j t}^{1}}{\bar{N}_{j t}^{1}}\right)^{\frac{\varrho-1}{\varrho}}+\left(\frac{s_{j t}^{2}}{S_{j t}}\right)^{\frac{1}{\varrho}} \cdot\left(\frac{N_{i j t}^{2}}{\bar{N}_{j t}^{2}}\right)^{\frac{\varrho-1}{\varrho}}\right)^{\frac{\varrho}{\varrho-1}}
\end{aligned}
$$

\footnotetext{
${ }^{13}$ For example, for $j=$ concrete and $\varkappa=$ cement, $s_{j t}^{\varkappa}$ would be approximately 0.53 , with slight variation across years.

${ }^{14}$ Continuing with the example from the previous footnote, $S_{j t}$ would be approximately $0.81(=0.28+0.53)$ for ready-mix concrete manufacturers.
} 
In Equation 4, $N_{i j t}$ is the number of units of the intermediate input bundle purchased by plant $i$ in industry $j$ and year $t$. Because the units of $N_{i j t}$ have no natural interpretation, it is necessary to normalize by the average input utilization of each of the intermediate goods, $\bar{N}_{j t}^{1}$ and $\bar{N}_{j t}^{2}$, in the given industry-year. ${ }^{15}$ Assumption 4 pins down how the two different materials are combined to form the composite intermediate input; relaxing Assumption 4 would involve allowing $\varrho>0$.

Let $P_{1 i j t}^{i n}$ and $P_{2 i j t}^{i n}$ be the price that plant $i$ of industry $j$ pays for materials 1 and 2 in year $t$, and let $\bar{P}_{1 j t}^{i n}$ and $\bar{P}_{2 j t}^{i n}$ be the corresponding industry-year averages. Then, the materials bundle's ideal price index equals the value-weighted average of the individual inputs' prices:

$$
P_{i j t}^{i n} \equiv \frac{s_{j t}^{1}}{S_{j t}} \cdot \frac{P_{1 i j t}^{i n}}{\bar{P}_{1 j t}^{i n}}+\frac{s_{j t}^{2}}{S_{j t}} \cdot \frac{P_{2 i j t}^{i n}}{\bar{P}_{2 j t}^{i n}}
$$

Having defined plant-level materials and output prices, I can now compute plantlevel productivities. For each plant, $i$, producing in industry $j$ and year $t$, define its quantity total factor productivity $(T F P Q)$ as the ratio between the physical quantity it produces and the inputs it utilizes in the production of this product: ${ }^{16}$

$$
T F P Q_{i j t} \equiv Q_{i j t} \cdot\left(L_{i j t}\right)^{-\lambda_{j t}} \cdot\left(K_{i j t}\right)^{-\kappa_{j t}} \cdot\left(E_{i j t}\right)^{-\epsilon_{j t}} \cdot\left(M_{i j t}\right)^{-\sigma_{j t}}
$$

In Equation $6, L_{i j t}, K_{i j t}$, and $E_{i j t}$ denote the amount of labor, capital, and energy used in the production of product $j$. As in Foster, Haltiwanger, and Syverson (2008), labor is stated in terms of hours, and capital is computed by summing plants' reported book values of equipment and structures. Note that, because of Assumption 1, the factor elasticities, $\lambda_{j t}, \kappa_{j t}, \epsilon_{j t}$ and $\sigma_{j t}$, are the same for all plants within an industry-year pair. In addition, $\lambda_{j t}+\kappa_{j t}+\epsilon_{j t}+\sigma_{j t}=1$ for all $j, t$ pairs. To emphasize, since $M_{i j t}=P_{i j t}^{i n} \cdot N_{i j t}$, low materials prices are associated with high TFPQ $Q_{i j t}$.

The industry-year specific cost shares in Equation 6 are computed as in Foster,

\footnotetext{
${ }^{15}$ Klump, McAdam, and William (2012) comprises a discussion of the necessity of normalizing CES production functions when $\varrho \neq 1$. (When $\varrho=1$, the units can be factored out into a multiplicative constant.)

${ }^{16}$ Ideally, I would compare the estimates generated by Equations 6-8 to those computed using other estimation methodologies. Unfortunately, like Foster, Haltiwanger, and Syverson (2008), I am unable to compute plant-level productivities using the methods outlined in Olley and Pakes (1995), Blundell and Bond (2000), and Ackerberg, Caves, and Frazer (2006). These methods generally require annual observations, while information on quantities of output produced or intermediate inputs purchased exist only for years in which the Census of Manufacturers is conducted. Most likely, my results would not change if other productivity measures were used. Van Biesebroeck (2008) reports that, unlike estimates of input elasticities, which are sensitive to the estimation methodology, plant-level productivity estimates are highly correlated across different estimation methodologies.

In Web Appendix A.5, I re-estimate plants' productivities, using the index number approach outlined in Caves, Christensen, and Diewert (1982). The main results of Section 3 are essentially unchanged.
} 
Haltiwanger, and Syverson (2008): I use industry-year level cost shares from the NBER Productivity database as estimates of the production function factor shares. Capital service expenditures are set equal to the value of the stock of capital multiplied by capital rental rates (from unpublished data constructed by the Bureau of Labor Statistics).

Revenue total factor productivity $(T F P R)$ captures a plant's ability to transform a given bundle of inputs into revenue. As Equation 7 makes clear, plants will have a high $T F P R$ for one of two reasons: Either they have high TFPQ, or they sell their output at a particularly high price:

$$
\begin{aligned}
\text { TFPR }_{i j t} & \equiv Y_{i j t} \cdot\left(L_{i j t}\right)^{-\lambda_{j t}} \cdot\left(K_{i j t}\right)^{-\kappa_{j t}} \cdot\left(E_{i j t}\right)^{-\epsilon_{j t}} \cdot\left(M_{i j t}\right)^{-\sigma_{j t}} \\
& =\operatorname{TFP} Q_{i j t} \cdot P_{i j t}^{\text {out }}
\end{aligned}
$$

Finally, when computing plants' technical efficiencies $\left(\Phi_{i j t}\right)$, I purge the materials price from measured productivity:

$$
\begin{aligned}
\Phi_{i j t} & \equiv Q_{i j t} \cdot\left(L_{i j t}\right)^{-\lambda_{j t}} \cdot\left(K_{i j t}\right)^{-\kappa_{j t}} \cdot\left(E_{i j t}\right)^{-\epsilon_{j t}} \cdot\left(M_{i j t}^{0}\right)^{-\sigma_{j t} \cdot\left(1-S_{j t}\right)} \cdot\left(N_{i j t}\right)^{-\sigma_{j t} \cdot S_{j t}} \\
& =Q_{i j t} \cdot\left(L_{i j t}\right)^{-\lambda_{j t}} \cdot\left(K_{i j t}\right)^{-\kappa_{j t}} \cdot\left(E_{i j t}\right)^{-\epsilon_{j t}} \cdot\left(M_{i j t}\right)^{-\sigma_{j t}} \cdot\left(P_{i j t}^{i n}\right)^{\sigma_{j t} \cdot S_{j t}} \\
& =T F P Q_{i j t} \cdot\left(P_{i j t}^{i n}\right)^{\sigma_{j t} \cdot S_{j t}}
\end{aligned}
$$

The equality of the first and second lines of Equation 8 follows from Assumption 5, namely the unitary elasticity of substitution between "priced" and "non-priced" materials. The equality of the second and third lines follows from the definition of $T F P Q$. Equation 8 states that plants will have high $T F P Q_{i j t}$ for one of two reasons: either the plant is technically efficient $\left(\Phi_{i j t}\right.$ is large), or materials prices are low ( $P_{i j t}^{i n}$ is low). ${ }^{17,18}$

Note that Assumptions 1 and 2 imply that TFPQ is inversely proportional to marginal costs. ${ }^{19}$ Given this, I will use the terms "low quantity productivity" and "high marginal

\footnotetext{
${ }^{17}$ Of course, there may be within-industry differences in the factor market conditions for labor, capital, and electricity. Because of Assumption 2, these differences would be incorrectly labeled as differences in technical efficiencies.

${ }^{18}$ To the extent that plants invest in finding suppliers that will charge a low price, stripping out materials price variation may do more harm than good. Following Foster, Haltiwanger, and Syverson (2008), I examine the relationship between plants' input prices and the share of workers that are not engaged in actual production. These workers are, potentially, the ones that are searching for new, low-cost suppliers. If this hypothesis is correct, plants that have a higher share of nonproduction workers will have lower-thanaverage materials prices. In the data, this turns out not to be the case. The correlation between a plant's ( $\log$ ) non-production worker share and its $p^{\text {in }}$ equals -0.00. Foster, Haltiwanger, and Syverson document a similar result: A higher nonproduction worker share is very weakly positively correlated with higher output prices. While this is a crude calculation, it suggests that plants' investments are not a driving source of materials price variation.

${ }^{19}$ Solving the cost minimization problem of a plant with a constant returns Cobb-Douglas production technology yields the following expression for its marginal cost: $M C_{i j t} \propto\left(\Phi_{i j t}\right)^{-1} \cdot\left(P_{i j t}^{i n}\right)^{\sigma_{j t} \cdot S_{j t}}=T F P Q^{-1}$.
} 
cost" interchangeably.

So that I can compare observations across industries and years, all quantities will be stated relative to the mean for that industry-year. I use lower-case letters to denote the percent deviation of a variable from its industry-year average. For any plant-level statistic, $X_{i j t}$, define:

$$
x_{i j t} \equiv \log \left(X_{i j t}\right)-\frac{\sum_{k: k \in i} \text { 's industry in year } \mathrm{t} \log X_{k j t}}{\|\{k: k \in i \text { 's industry in year } \mathrm{t}\} \|}
$$

\subsection{Relationships Among Prices and Productivity Measures}

Before proceeding to the empirical analysis, I provide expressions for the relationships among the different productivity measures and plant-level prices. ${ }^{20} \mathrm{I}$ will take $\phi_{i j t}$ and $p_{i j t}$ in as given and use Equations 6-9 to characterize the signs of the relationships between the plant-level productivity measures and input prices. In general, $\phi_{i j t}$ and $p_{i j t}^{i n}$ emerge from the interactions between plant $i$ 's choices (on how much to produce, how much of each input to purchase, how much effort to spend searching for low cost inputs, etc.) and conditions in factor and output markets. For this discussion, it suffices to leave these decisions and interactions unmodeled.

In this subsection, I assume that $\operatorname{Cov}\left(\phi, p^{i n}\right) \approx 0$. That is, in the observed sample, there is no relationship between plants' technical efficiencies and the prices at which they purchase intermediate inputs. As Table 2 will demonstrate, there is actually a weak positive relationship between materials prices and technical efficiencies. Ignoring this positive relationship, for the moment, yields simple expressions for the relationships of interest. In conjunction with the definitions given in Equations 6-9, this subsection's assumption yields:

$$
\begin{aligned}
\operatorname{Cov}(t f p q, \phi) & =\operatorname{Var}(\phi)>0 \\
\operatorname{Cov}\left(t f p q, p^{i n}\right) & =-\sigma \cdot S \cdot \operatorname{Var}\left(p^{i n}\right)<0 \\
\operatorname{Var}(t f p q)-\operatorname{Var}(\phi) & =(\sigma S)^{2} \cdot \operatorname{Var}\left(p^{i n}\right)>0
\end{aligned}
$$

Equation 10 states that plants with high technical efficiencies also have higher-thanaverage quantity productivities. Moreover, plants that purchase their inputs cheaply have high $t f p q$ 's (low marginal costs). Finally, $t f p q$ is more dispersed than $\phi$. To provide some intuition for the sign of Equation 12, notice that $t f p q$ is the difference of $\phi$ and $p^{i n}$. As long as the relationship between technical efficiency and input prices is not too strong, which, for

The constant of proportionality is a function of the industry-year specific unit costs of labor, capital, and electricity.

${ }^{20}$ The exposition of this subsection is due, in large part, to an anonymous referee, to whom I am deeply thankful. 
now I am assuming, the variance of $t f p q$ will have to be larger than the variance of $\phi$.

There are other relationships of interest, among plants' output prices, revenue productivities, and quantity productivities. A simple model generating predictions over these relationships can be found in Foster, Haltiwanger, and Syverson (2008). Their set-up yields the following predictions: Plants with low marginal costs (high $t f p q$ ) will have higher-thanaverage markups, but lower-than-average output prices. Thus, $p^{\text {out }}$ will be positively correlated with $t f p r$, but negatively correlated with $t f p q$. I check these predictions, in addition to the more novel predictions given in Equations 10-12, in the following section.

\section{Implications of Materials Price Dispersion}

In this section, I explore some of the implications of price dispersion in intermediate input markets. In Section 3.1, I document that materials price dispersion is substantial and provide correlations among plant-level statistics. In Section 3.2, I estimate that 7\% to $10 \%$ of the variation in $t f p q$ is attributable to differences in the materials prices that plants face. In Section 3.3, I argue that the price that plants face when purchasing their materials is persistent across time and correlated across space. In Section 3.4, I show that materials

prices are higher for plants that are about to exit. Finally, in Section 3.5, I compute the contribution, towards aggregate productivity growth, of the entry of relatively productive plants and the exit of relatively unproductive plants.

\subsection{Descriptive Statistics}

Table 2 contains summary statistics for the plant-level productivities and input/output prices. All plant-level variables are de-meaned by industry-year according to Equation 9 .

The first takeaway from Table 2 is that within-industry price dispersion is substantial. For the benchmark sample which, again, consists of plants that produce commodity-like products, the within-industry standard deviations of plant-level materials and output prices are approximately $12 \%$. These dispersions are of similar magnitude to the within-industry variation in plant productivities.

What is more, the observed correlations in Table 2 match the predictions made in Section 2.5. The correlation coefficients between $t f p q, t f p r$, and $p^{\text {out }}$ are similar to those computed in Foster, Haltiwanger, and Syverson (2008). Plants with higher tfpq pass on some of their lower marginal costs to their consumers (generating a low $p^{\text {out }}$ ). In addition, tfpq and $t f p r$ are positively correlated, as are $t f p r$ and $p^{\text {out }}$.

The variables that are new to this study are $\phi$ and $p^{i n}$, log technical efficiencies and 


\begin{tabular}{lccccc}
\hline & $p^{\text {in }}$ & $p^{\text {out }}$ & $t f p q$ & $\phi$ & $t f p r$ \\
\hline$p^{\text {out }}$ & $0.231^{*}$ & & & & \\
$t f p q$ & $-0.369^{*}$ & $-0.551^{*}$ & & & \\
$\phi$ & $0.127^{*}$ & $-0.469^{*}$ & $0.873^{*}$ & & \\
tfpr & $-0.232^{*}$ & $0.219^{*}$ & $0.616^{*}$ & $0.694^{*}$ & \\
Std. Dev. & 0.117 & 0.119 & 0.161 & 0.151 & 0.137 \\
\hline
\end{tabular}

Table 2: Correlations and standard deviations of plant-level characteristics.

Notes: Observations are weighed by plants' real revenues. Stars indicate that the correlation is significantly different from 0, at the 5\% level (see Web Appendix C for details). Correlations for each of the 10 industries are presented in Web Appendix A.6, while correlations that give plant-year observations equal weight are given in Web Appendix A.8. $\mathrm{N}=10,503$.

log materials prices. First, plant-level materials prices, $p^{i n}$, are negatively correlated with $t f p q$ and $t f p r$. Plants that purchase inputs cheaply appear to be more productive according to the conventional measures. At the same time, $t f p q$ and $\phi$ are highly correlated with one another, while the correlation between $\phi$ and $t f p r$ is similar to the correlation between $t f p r$ and $t f p q$.

Materials prices are positively correlated with output prices and technical efficiencies. There are several possible explanations for these positive relationships. First, the correlations may reflect any differences in input and output quality that still remain (despite my best efforts to choose a sample of industries with outputs and material inputs that are comparable across plants). If a) inputs vary in quality, b) these quality differences are reflected by differences in materials prices, and c) high-quality inputs allow a plant to produce more units of a given product using a given bundle of inputs (measured in physical units), then we will observe a positive correlation between $\phi$ and $p^{i n}$. Quality variation may also explain why $p^{\text {out }}$ and $p^{\text {in }}$ are correlated with one another, to the extent that inputs vary considerably in quality and consumers value products that are produced using high-quality material inputs.

A second possible explanation is that a selection mechanism, one on plant survival, may be causing us to observe a positive relationship between $p^{\text {out }} / \phi$ and $p^{\text {in }}$ : If plants' survival depends on their profitability being above some cutoff, plants will be able to tolerate poor conditions in input markets if they are able to sell their output expensively or if they are particularly technically efficient.

Finally, independent of quality differences or selection, the positive correlation between input and output prices may be due to imperfections in output markets, where high materials prices can at least partially be passed through to the establishments' customers. 


\subsection{Implications for Productivity Dispersion}

In this subsection, I compare the dispersions of the distributions of $t f p q$ and $\phi$. In so doing, I provide a measure of the fraction of $t f p q$ dispersion that can be explained by differences in intermediate input prices. The main finding, that the dispersion of $t f p q$ exceeds the dispersion of $\phi$, is the prediction of Equation 12.

Pooling across the 10 industries in the sample, the standard deviation of $\phi$ is $16.3 \%$ $\left(=e^{0.151}\right)$, while the standard deviation of $t f p q$ is $17.5 \%, 7 \%$ larger than the standard deviation of $\phi$. So, by eliminating the effect of differences in materials prices, the observed distribution of productivities would be approximately $7 \%$ lower; the $95 \%$ confidence interval of the difference between the standard deviations of $t f p q$ and $\phi$ is $[0.2 \%, 10.4 \%]$. Table 3 includes two other measures of dispersion, the 90/10 ratio and the $75 / 25$ ratio. The difference between the dispersions of $t f p q$ and $\phi$ is somewhat greater with these two alternate measures: $9 \%$ for the $90 / 10$ ratio and $10 \%$ for the $75 / 25$ ratio.

The difference between $t f p q$ and $\phi$ varies across industries, particularly for the industries with small sample sizes. For coffee, $t f p q$ is $17 \%$ to $30 \%$ more dispersed than $\phi$, while $\phi$ actually displays more dispersion than $t f p q$ for the smallest-sample industry, raw cane sugar.

Even though I have chosen industries based on the homogeneity of the inputs and outputs, it is likely that at least some of the variation in materials and output prices is due to differences in quality. Variation in input/output quality attenuates the negative correlation between $t f p q$ and $p^{i n}$ (see Appendices A.1 and A.2, where I study samples with more pronounced input/output quality variation). High-quality material inputs, for example, will allow establishments to produce and sell more using a given measured quantity of material inputs. To the extent that high-quality intermediate inputs are purchased at higher unit prices, this will induce a positive relationship between $\phi$ and $p^{i n}$. As a result, then, withinindustry variation in quality will lead to a downward bias in the measured difference between the dispersion of $t f p q$ and the dispersion of $\phi .{ }^{21}$ In other words, the $7 \%$ to $10 \%$ decline in dispersion most likely underrepresents the actual fraction of $t f p q$ dispersion that is due to differences in materials prices.

Measurement error has the potential to bias the correlations given in Table 2 and the dispersions given in Tables 3 and 4. Because $P_{i j t}^{i n}$ is constructed by taking the ratio of $M_{i j t}$ and $N_{i j t}$, any measurement error in $N_{i j t}$ will induce spurious positive correlation between

\footnotetext{
${ }^{21}$ Since

$$
\operatorname{Var}(t f p q)=\operatorname{Var}(\phi)+(\sigma S)^{2} \operatorname{Var}\left(p^{i n}\right)-2 \sigma S \cdot \operatorname{Cov}\left(\phi, p^{i n}\right),
$$

any positive correlation between $\phi$ and $p^{\text {in }}$ will lead to a decline in the dispersion of $t f p q$ relative to that of $\phi$.
} 


\begin{tabular}{|c|c|c|c|c|c|c|c|c|c|}
\hline & \multicolumn{3}{|c|}{ Dispersion of $t f p q$} & \multicolumn{3}{|c|}{ Dispersion of $\phi$} & \multicolumn{3}{|c|}{ Percent Decrease } \\
\hline Sample & $90 / 10$ & $75 / 25$ & SD & $90 / 10$ & $75 / 25$ & SD & $90 / 10$ & $75 / 25$ & SD \\
\hline Boxes, Yr. $\leq 87$ & 0.380 & 0.179 & 0.168 & 0.366 & 0.177 & 0.166 & $3.7 \% *$ & $1.0 \%$ & $1.6 \%$ \\
\hline Boxes, Yr. $\geq ' 92$ & 0.566 & 0.293 & 0.225 & 0.526 & 0.276 & 0.211 & $7.9 \% *$ & $6.2 \% *$ & $6.7 \% *$ \\
\hline Coffee & 0.709 & 0.326 & 0.266 & 0.562 & 0.277 & 0.229 & $30.1 \% *$ & $19.5 \% *$ & $17.4 \% *$ \\
\hline Concrete & 0.521 & 0.251 & 0.224 & 0.486 & 0.236 & 0.215 & $7.4 \% *$ & $6.6 \% *$ & $4.4 \% *$ \\
\hline Flour & 0.360 & 0.190 & 0.142 & 0.349 & 0.158 & 0.148 & $3.2 \%$ & $23.2 \% *$ & $-4.1 \%$ \\
\hline $\mathrm{Ga}$ & 0.300 & 0.1 & 0.132 & 0.280 & 0.133 & 0.122 & $7.6 \%$ & $9.5 \%$ & $8.1 \%$ \\
\hline Mill & 0.597 & 0.285 & 0.252 & 0.531 & 0.267 & 0.229 & $13.1 \%$ & $7.2 \%$ & $10.3 \%$ \\
\hline Milk, Packaged & 0.535 & 0.261 & 0.227 & 0.502 & 0.248 & 0.218 & $6.7 \% *$ & $5.3 \% *$ & $4.1 \% *$ \\
\hline Sugar & 0.588 & 0.297 & 0.280 & 0.766 & 0.340 & 0.319 & $-20.7 \%$ & $-11.9 \%$ & $-11.5 \% *$ \\
\hline Yarn & 0.581 & 0.275 & 0.256 & 0.633 & 0.310 & 0.252 & $-8.0 \%$ & $-10.8 \%$ & $1.5 \%$ \\
\hline $\begin{array}{l}\text { Pooled: } \\
\text { Weighted }\end{array}$ & 0 & 0 & 1 & 24 & 51 & 0.151 & * & $9.7 \%$ & $0^{*}$ \\
\hline $\begin{array}{l}\text { Pooled: } \\
\text { Unweighted }\end{array}$ & 0.527 & 0.253 & 0.227 & 0.493 & 0.238 & 0.219 & $7.2 \%^{*}$ & $6.5 \%^{*}$ & $3.9 \% *$ \\
\hline
\end{tabular}

Table 3: Dispersion of $t f p q$ and $\phi$.

Notes: In the final three columns, stars indicate that the difference between $t f p q$ and $\phi$ is statistically significant, at the $5 \%$ level (see Web Appendix C for details). Except for the final row, observations are weighed by plants' real revenues. See Web Appendix A.8 for the unweighted computations, broken out by industry. $^{22}$

$p^{i n}$ and $\phi$. Similarly, because plant-specific output prices $\left(P_{i j t}^{\text {out }}\right)$ are computed by taking the ratio of revenues $\left(Y_{i j t}\right)$ to quantities produced $\left(Q_{i j t}\right)$, measurement error in $Q_{i j t}$ will tend to engender negative correlations between $p^{\text {out }}$ and $t f p q / \phi$. In turn, measurement error in $N_{i j t}$ and $Q_{i j t}$ has the potential to bias the dispersions of $t f p q$, and $\phi$. I explore the magnitude of these biases in Web Appendix A.7. The main takeaway from Web Appendix A.7 is that measurement error will also lead me to understate the difference between the dispersion of tfpq and the dispersion of $\phi$.

With these caveats in mind, I now relate the $7 \%$ to $10 \%$ decline in dispersion to dispersion declines reported in two other papers. First, Syverson (2004b) hypothesizes that, in markets for which competitive forces are exceptionally strong, low productivity plants are more likely to exit the industry, in turn leading to a more compressed productivity distribution. Within the ready-mix concrete industry, Syverson characterizes areas with high densities of construction activity as highly competitive markets, and finds that this demand density index explains approximately $2 \%$ of the cross-market variation in the dispersion of measured productivity. In a second example, Fox and Smeets (2011) compute the fraction of measured productivity dispersion that can be explained by differences in worker quality. While Fox and Smeets' application of a value-added production function muddles a comparison of magnitudes, it is likely that materials price variation is at least as important - in 


\begin{tabular}{cccccccccc}
\hline Revenue- & \multicolumn{3}{c}{ Dispersion of $t f p r$} & \multicolumn{3}{c}{ Dispersion of $t f p q$} & \multicolumn{3}{c}{ Percent Increase } \\
weighted? & $90 / 10$ & $75 / 25$ & SD & $90 / 10$ & $75 / 25$ & SD & $90 / 10$ & $75 / 25$ & SD \\
\hline Yes & 0.306 & 0.147 & 0.137 & 0.351 & 0.164 & 0.161 & $16.0 \%^{*}$ & $12.9 \%$ & $18.5 \%^{*}$ \\
No & 0.380 & 0.178 & 0.176 & 0.527 & 0.253 & 0.227 & $47.3 \%^{*}$ & $53.0 \%^{*}$ & $33.7 \%^{*}$ \\
\hline
\end{tabular}

Table 4: Dispersion of $t f p r$ and $t f p q$.

Notes: In the final three columns, stars indicate that the difference between $t f p r$ and $t f p q$ is statistically significant, at the $5 \%$ level (see Web Appendix C for details). N=10,503.

terms of reducing measured productivity dispersions - as labor-quality variation. ${ }^{23}$

While price dispersion in intermediate input markets tends to reduce the dispersion of measured productivity (i.e., the dispersion of $t f p q$ is greater than that of $\phi$ ), price dispersion in output markets has the opposite effect on the dispersion of measured productivity (i.e., the dispersion $t f p r$ is smaller than that of $t f p q$ ). The latter relationship, which Foster, Haltiwanger, and Syverson (2008) also document, stems from the strong negative correlation between $p^{\text {out }}$ and $t f p q$ : The standard deviation of revenue productivity, which is $14.7 \%$ in the revenue-weighted calculations, is approximately $19 \%$ smaller than the standard deviation of quantity productivity. In this sense, $\phi$ and $t f p r$ are closer to each other than one might presume. The similarity of these two productivity measures is intuitive; it stems from the positive correlation between input and output prices. The countervailing effects - as in this case, on the standard deviation of measured productivity - of factor price dispersion and output price dispersion will be a recurring finding in the remainder of this section.

\footnotetext{
${ }^{22}$ Due to Census' rules regarding data confidentiality, I am prohibited from reporting the actual quantiles of any empirical distribution. The quantiles (but not the standard deviations, which are not subject to this regulation) are computed in a two-step process. First, using a kernel density estimator, I produce a smoothed version of the empirical cumulative distribution function of the variable of interest. I then report the quantile of this smoothed distribution. The decrease in productivity dispersion-between $t f p q$ and $\phi$ is not substantially affected by this smoothing procedure. I employ the same two-step procedure in the calculations of Tables 4, 14, 17, 20, and 27.

${ }^{23}$ Within four manufacturing industries, Fox and Smeets (2011) report a 14\% decline in the 90/10 ratio of measured productivities, after including rich controls for worker quality. (The wage bill alone reduces the 90/10 ratio by almost as much, 13\%.) However, as Gandhi, Navarro, and Rivers (2012) argue, value-added production functions cause one to overstate productivity dispersion and to infer "fundamentally different patterns of productivity heterogeneity." (p. 1)

I compute the decline in measured productivity dispersion accrued by replacing hours with wages as the measure of labor inputs, still using, as I have been throughout the paper, a gross output production function. For the 10 industries in my benchmark sample, the $90 / 10$ ratio declines by $2.4 \%$ if observations are revenue weighted, and $6.6 \%$ if observations are given equal weight.
} 


\begin{tabular}{lccccccccc}
\hline & $\begin{array}{l}\text { Revenue- } \\
\text { weighted? }\end{array}$ & $t f p q$ & $t f p r$ & $p^{\text {out }}$ & $\phi$ & $p^{\text {in }}$ & $y$ & $q$ & $n$ \\
\hline$\beta$ & No & $0.351^{*}$ & $0.306^{*}$ & $0.432^{*}$ & $0.299^{*}$ & $0.309^{*}$ & $0.895^{*}$ & $0.901^{*}$ & $0.889^{*}$ \\
s.e. & No & $(0.022)$ & $(0.024)$ & $(0.024)$ & $(0.023)$ & $(0.025)$ & $(0.010)$ & $(0.009)$ & $(0.010)$ \\
$\beta^{1 / 5}$ & No & 0.811 & 0.789 & 0.846 & 0.786 & 0.791 & 0.978 & 0.979 & 0.977 \\
$\beta$ & Yes & 0.175 & 0.201 & $0.305^{*}$ & $0.185^{*}$ & $0.326^{*}$ & $0.868^{*}$ & $0.868^{*}$ & $0.885^{*}$ \\
$s . e$. & Yes & $(0.092)$ & $(0.106)$ & $(0.040)$ & $(0.083)$ & $(0.047)$ & $(0.045)$ & $(0.051)$ & $(0.028)$ \\
$\beta^{1 / 5}$ & Yes & 0.706 & 0.726 & 0.789 & 0.713 & 0.799 & 0.972 & 0.972 & 0.976 \\
\hline
\end{tabular}

Table 5: Persistence of plant-level characteristics.

Notes: Stars indicate significance at the $5 \%$ level. $\mathrm{N}=4310$.

\subsection{Serial and Spatial Correlation}

A long stream of research, beginning with Baily, Hulten, and Campbell (1992), has documented the persistence of plant-level characteristics. Using regressions of the form,

$$
x_{i, j, t+5}=\alpha+\beta \cdot x_{i j t}+\varepsilon_{i j t},
$$

Foster, Haltiwanger, and Syverson (2008) compute the 1 and 5-year autocorrelation coefficients for different plant-level statistics. They compute that plant-level productivities and output prices have a 1-year autocorrelation coefficient of approximately $70 \%$ to $80 \%$. I replicate these findings in Table 5. The novel components of Table 5 appear in the final five columns. I find that the persistence of $\phi$ is similar to that of the two other plant-level productivity measures, and that the persistence of $p^{\text {in }}$ is similar to the persistence of $p^{\text {out }}$. Measures of plant size - revenues and physical quantities of outputs and intermediate inputs - exhibit significantly more persistence relative to the productivity and price measures.

There are at least three potential explanations as to why materials price variation is so persistent. A first possibility is that the price variation reflects residual, persistent, within-industry differences in the quality of plants' inputs. Again, while this possibility should not completely be discounted, I have selected industries with little quality variation to mitigate its role in my analysis. Second, persistence of materials price variation might result from long-term buyer-supplier relationships, a possibility I explore in Sections 4.24.3. A third possibility, which I will also re-visit in Section 4.2, is that geographical forces generate persistent within-industry variation in materials prices.

To examine this final possibility, I measure the extent to which materials prices are spatially correlated. ${ }^{24}$ In particular, I run a regression on the benchmark sample of 10,503

\footnotetext{
${ }^{24}$ Geographical price variation could potentially reflect differences in demand for high-quality inputs, across locations. See Appendix A.2 for a discussion of the ready-mix concrete industry, an industry for which this might be the case.
} 


\begin{tabular}{lccc}
\hline \multicolumn{1}{c}{ Sample } & $\beta$ & s.e. & Adjusted $R^{2}$ \\
\hline Boxes, Yr. $\leq 87$ & 0.884 & 0.080 & 0.063 \\
Boxes, Yr. $\geq 92$ & 0.693 & 0.120 & 0.048 \\
Coffee & 0.051 & 0.080 & -0.002 \\
Concrete & 0.913 & 0.028 & 0.222 \\
Flour & 0.266 & 0.091 & 0.015 \\
Gasoline & 0.721 & 0.056 & 0.193 \\
Milk, Bulk & 0.139 & 0.118 & 0.003 \\
Milk, Packaged & 0.826 & 0.041 & 0.160 \\
Sugar & 0.193 & 0.183 & 0.001 \\
Yarn & -0.377 & 0.308 & 0.001 \\
Pooled & 0.577 & 0.016 & 0.107 \\
\hline
\end{tabular}

Table 6: Spatial correlation of materials prices.

Notes: The dependent variable is $p_{i j t}^{i n}$, and the independent variable is the (revenue-weighted) average of the $p_{i^{\prime} j t}^{i n}$ for the plants that are within a 250-mile radius of plant $i$ in industry $j$ and year $t$. Observations are revenue weighted. See Web Appendix A.8 for the unweighted version of this table.

plant-year observations. In this regression, the dependent variable is the materials price for plant $i$ in year $t, p_{i j t}^{i n}$. The sole independent variable is the revenue-weighted average of the materials prices of the other plants that are located within 250 miles of plant $i$. (I find similar results using a range of alternate cutoffs.) Table 6 indicates that $11 \%$ of materials price variation is explained by the materials prices of nearby plants. Materials prices for gasoline refiners and concrete manufacturers exhibit the strongest spatial correlation, while the materials prices of bulk milk, yarn, coffee, and sugar manufacturers are not spatially correlated.

\subsection{Characteristics of Entering and Exiting Plants}

In this subsection, I compare the prices and productivity measures of entering plants with incumbent plants and exiting plants with surviving plants. Table 7 presents the main results of this subsection, the results of the regressions defined by Equations 14 and $15 .^{25}$

$$
\begin{aligned}
& x_{i j t}=\alpha_{j t}+\beta_{1} \cdot \mathbb{I}\{i \in \text { plants that enter between years } t-5 \text { and } t\}+\varepsilon_{i j t} \\
& x_{i j t}=\zeta_{j t}+\beta_{2} \cdot \mathbb{I}\{i \in \text { plants that exit between years } t \text { and } t+5\}+\varepsilon_{i j t}
\end{aligned}
$$

Like Foster, Haltiwanger, and Syverson (2008), I find that entrants/exiting plants are significantly smaller than the average plant in a given industry-year, and that exiting plants have significantly lower $\phi, t f p q$, and $t f p r$. The productivity advantage of entrants (and

\footnotetext{
${ }^{25}$ To emphasize, exit (and entry) are defined on the basis of true exit and entry from the overall population of establishments, not simply exit (or entry) from the benchmark sample.
} 


\begin{tabular}{lccccccc}
\hline $\begin{array}{l}\text { Coefficient } \\
\text { on: }\end{array}$ & $\begin{array}{l}\text { Revenue- } \\
\text { weighted? }\end{array}$ & $t f p q$ & $\phi$ & $t f p r$ & $y$ & $p^{\text {in }}$ & $p^{\text {out }}$ \\
\hline Entry & No & $0.017^{*}$ & $0.020^{*}$ & $0.015^{*}$ & $-0.456^{*}$ & 0.005 & -0.002 \\
Entry & No & $(0.008)$ & $(0.007)$ & $(0.006)$ & $(0.032)$ & $(0.006)$ & $(0.006)$ \\
Entry & Yes & 0.009 & -0.004 & -0.005 & $-0.698^{*}$ & -0.019 & -0.014 \\
Entry & Yes & $(0.025)$ & $(0.023)$ & $(0.022)$ & $(0.092)$ & $(0.015)$ & $(0.016)$ \\
Exit & No & $-0.025^{*}$ & $-0.016^{*}$ & $-0.020^{*}$ & $-0.534^{*}$ & $0.014^{*}$ & 0.005 \\
Exit & No & $(0.007)$ & $(0.007)$ & $(0.006)$ & $(0.031)$ & $(0.005)$ & $(0.006)$ \\
Exit & Yes & $-0.051^{*}$ & $-0.042^{*}$ & -0.039 & $-0.609^{*}$ & 0.013 & 0.012 \\
Exit & Yes & $(0.018)$ & $(0.016)$ & $(0.020)$ & $(0.131)$ & $(0.012)$ & $(0.012)$ \\
\hline
\end{tabular}

Table 7: Comparison of plant-level statistics and entry/exit status.

Notes: In the first four rows, each cell gives the coefficient estimate, or standard error, of $\beta_{1}$ in Equation 14. In the final four rows, each cell gives the coefficient estimate, or standard error, of $\beta_{2}$ in Equation 15. Stars denote significance at the $5 \%$ level. $\mathrm{N}=10,503$.

productivity disadvantage of exiting plants) is larger for quantity productivity than it is for revenue productivity: Removing the output-price component of revenue productivity tends to increase the difference between surviving and exiting plants' productivities.

In addition to these already-known empirical regularities, I find that exiting plants pay approximately $1.4 \%$ (1.3\% for the revenue-weighted calculations) more per unit of the intermediate input than the surviving plants in their industry-year. The positive relationship between materials prices and the probability of exit reinforces my presumption of insubstantial quality variation in the benchmark sample: High materials prices are a burden to bear, not a marker of high-quality type, as in, for example, Kugler and Verhoogen (2012).

Comparing the first two columns of Table 7, the productivity advantage of surviving plants is larger for $t f p q$ than it is for $\phi$ : Removing the materials-price component of quantity productivity marginally decreases the measured difference between surviving and exiting plants' productivities.

The results in Table 7 indicate that the productivity advantage of entrants (compared to incumbents) and surviving plants (compared to exiting plants) is highest when using $t f p q$ as the productivity measure. In other words, controlling for output prices but not materials prices tends to make entrants (survivors) appear relatively more productive than incumbents (exiting plants). The next subsection considers the magnitude and significance of the differences, across the three productivity measures, of the importance of reallocation via plants' entry and exit. 


\subsection{Decompositions of Industry Productivity Growth}

In this subsection, I compute the fraction of aggregate productivity growth that occurs via the net entry effect: the exit of relatively unproductive plants and the entry of relatively productive plants. The extent to which reallocation across plants explains aggregate productivity growth has been extensively studied (e.g., Baily, Hulten, and Campbell 1992; Griliches and Regev 1995; Foster, Haltiwanger, and Krizan 2001; and Foster, Haltiwanger, and Syverson 2008). Of these analyses, I am most closely following Foster, Haltiwanger, and Syverson (2008), who compute the net entry effect when either $t f p r$ or $t f p q$ is used as the measure of plant productivity. Because entrants charge lower prices than incumbents, the net entry effect is smaller when revenue productivity measures are used instead of quantity productivity measures. The authors conclude that, "in terms of understanding the barriers to allocative efficiency... revenue based productivity decompositions may focus too much attention on continuing businesses and not enough on the role of entering businesses." (p. 419) Below, I show that accounting for materials prices partially reverses this finding.

Like Foster, Haltiwanger, and Syverson (2008), I use the following growth decomposition, due to Baily, Hulten, and Campbell (1992) and Foster, Haltiwanger, and Krizan (2001):

$$
\begin{aligned}
\Delta \overline{t f p}_{t}= & \sum_{i \in \mathcal{C}} \theta_{i, t-1} \cdot \Delta t f p_{i t}+\sum_{i \in \mathcal{C}}\left(t f p_{i, t-1}-\overline{t f p}_{t-1}\right) \cdot \Delta \theta_{i t}+\sum_{i \in \mathcal{C}} \Delta t f p_{i t} \cdot \Delta \theta_{i t} \\
& +\underbrace{\sum_{i \in \mathcal{N}} \theta_{i t} \cdot\left(t f p_{i t}-\overline{t f p}_{t-1}\right)-\sum_{i \in \mathcal{X}} \theta_{i, t-1} \cdot\left(t f p_{i, t-1}-\overline{t f p}_{t-1}\right)}_{\text {Entry Effect }}
\end{aligned}
$$

In Equation 16, $\theta_{i t}$ denotes the revenue share of plant $i$, within its industry, in year $t ; \overline{t f p}_{t}$ gives the revenue-weighted average (log) productivity in year $t ; \Delta$ is the difference operator; and $\mathcal{C}, \mathcal{N}$, and $\mathcal{X}$ are the sets of continuing, entering, and exiting plants. The decomposition highlights the different sources of industry productivity growth, including the Entry Effect, the Exit Effect, and the sum of the two effects (the Net Entry Effect). ${ }^{26}$ The magnitudes of these three effects will depend on the productivity measure either $t f p r, t f p q$, or $\phi$-used in Equation 16.

The results of the industry decompositions are given in Table 8. I decompose the productivity growth - over 5-year intervals - separately for each of the 10 industries in the benchmark sample. The values are the averages over these 10 industries. In the first four

\footnotetext{
${ }^{26}$ Since a large number of plants enter and exit my benchmark sample without actually entering or exiting their industries, I will be unable to distinguish among the sources of aggregate productivity growth that are listed in the first line of Equation 16.
} 


\begin{tabular}{c|c|ccc|c|ccc}
\hline $\begin{array}{c}\text { Productivity } \\
\text { Measure }\end{array}$ & Total & Entry & Exit & $\begin{array}{l}\text { Net } \\
\text { Entry }\end{array}$ & Total & Entry & Exit & $\begin{array}{l}\text { Net } \\
\text { Entry }\end{array}$ \\
\hline$t f p r$ & -1.60 & -0.08 & 0.08 & 0.00 & 1.30 & 0.23 & 0.12 & 0.35 \\
$t f p q$ & -1.60 & -0.06 & 0.15 & 0.09 & 1.30 & 0.32 & 0.12 & 0.44 \\
$\phi$ & -1.60 & -0.09 & 0.13 & 0.04 & 1.30 & $0.25^{*}$ & 0.14 & 0.39 \\
\hline
\end{tabular}

Table 8: Aggregate productivity growth decompositions.

Notes: All values are given as percentages, over five-year horizons. In the first four columns, industries are assigned importance according to their total revenues. In the last four columns, industries are assigned importance according to the number of plants. Stars indicate that the value given in the cell is significantly different than the corresponding value that uses $t f p q$ as the measure of plant productivity. See Web Appendix C for details.

columns, industries with larger revenues (primarily gasoline manufacturing) are given more weight, while, in the last four columns, industries' weights are determined by the number of plants in the industry. The main takeaway from the table is that the Net Entry term is larger for quantity productivity $(t f p q)$ than it is for either revenue productivity $(t f p r)$ or technical efficiency $(\phi)$. Consistent with Foster, Haltiwanger, and Syverson (2008), Table 8 indicates that the contribution of net entry to aggregate productivity is larger when output prices are accounted for. At the same time, accounting for materials prices reduces the measured contribution of net entry to industry productivity growth. These patterns are robust to the decomposition method and the relative weights given to different industries. ${ }^{27}$

For completeness' sake, I assess the statistical significance of the differences, across the productivity measures, of the importance of the Entry, Exit, or Net Entry terms. When industries are weighed by the number of plants, the Entry Effect is significantly greater when $\phi$-instead of $t f p q$-is used as the productivity measure. Other differences are not statistically significant.

To summarize, the conventional productivity measures, $t f p q$ and $t f p r$, reflect withinindustry differences in materials prices. Because exiting plants face relatively high materials prices, and because (large) entrants pay relatively low prices, the difference between the productivity of exiting and surviving plants (and between entrants and incumbents) is larger for productivity measures that embody plants' materials prices. As a result, the contribution

\footnotetext{
${ }^{27}$ Foster, Haltiwanger, and Syverson (2008) consider a second growth decomposition, due to Griliches and Regev (1995). I show, in Web Appendix A.9, that this alternate decomposition method yields results very similar to those presented in Table 8.

One problem with the productivity growth decompositions originates from the overrepresentation of large plants in the benchmark sample. Because of this, entering and exiting plants are underrepresented in the benchmark sample, and the decompositions understate the role of net entry as a source of aggregate productivity growth. In Web Appendix A.10, I show that the qualitative patterns of this subsection (in particular, the difference, in the size of the Net Entry Effect between the three productivity measures) hold after correcting for the underrepresentation of entering and exiting plants.
} 
of reallocation, via entry and exit, is smaller for the productivity measure, $\phi$, that is cleansed of materials prices. These differences, however, are small and only of marginal statistical significance.

\section{Sources of Materials Price Dispersion}

I discuss three explanations for the observed within-industry dispersion of intermediate input prices. The sources of materials price dispersion have implications for the social benefits generated by each plant. Plants that pay low materials prices by taking advantage of monopsonistic power are not providing any societal benefit: Low materials prices are a transfer of profits from supplier to buyer. On the other hand, if plants pay low materials prices because their suppliers are exceptionally productive, low materials prices represent a positive impact on social welfare. The fraction of these welfare benefits that accrue to consumers will depend, in turn, on the degree to which lower input prices are passed on to final consumers.

To calculate the relative importance of these different sources of materials price dispersion, I need to impute, for each manufacturer, the identities of its suppliers. I outline, in Section 4.1, the algorithm that I use to impute buyer-supplier relationships. In Section 4.2, I compute the fraction of dispersion in $t f p q$ and $p^{i n}$ that can be explained by plants' geographic locations, their suppliers' marginal costs, and within-supplier deviations. A positive correlation between plants' materials prices and their suppliers' marginal costs stimulates the following question: If plants with low marginal cost suppliers pay less for their inputs, and if having low materials prices is so advantageous, then what prevents plants from purchasing their materials from the low marginal cost suppliers? In Section 4.3, I argue that buyersupplier relationships are persistent, suggesting that there is some inertial force that inhibits all plants from switching to low marginal cost suppliers. ${ }^{28}$

\subsection{Imputation of Buyer-Supplier Relationships}

To impute buyer-supplier relationships, I use the algorithm introduced in Atalay, Hortaçsu, and Syverson (2013). The algorithm generates a list of establishments that could potentially receive any shipment that is observed in the Commodity Flow Survey. Consider a hypothetical shipment of commodity, $c$, made by establishment, $h$, to zip code, $z$. The establishments, $i$, that could potentially receive this shipment are those who are located in

\footnotetext{
${ }^{28}$ Foster, Haltiwanger, and Syverson (2008) provide additional anecdotal evidence for the importance of relationship capital; see footnotes 23 and 24 of their paper.
} 
$z$ and are members of an industry that use $c$. For example, the potential recipients of a shipment of Portland cement to $z$ would be all plants in that zip code that are engaged in road construction, concrete brick manufacturing, ready-mix concrete manufacturing, or wholesaling of brick, stone, and related materials. If there are multiple potential recipients of the shipment, and one of these establishments is owned by the same firm as the sending establishment, then I assume that the shipment is received by the same-firm establishment. ${ }^{29}$ Otherwise, I assign each potential recipient, $i$, to be downstream of plant $h .^{30}$

In order to compute suppliers' marginal costs, I require the upstream industry to also be part of the manufacturing sector. Of the 10 industries in the benchmark sample, only two - ready-mix concrete and corrugated boxes - have a main input that is produced by a manufacturer. The industries with establishments that could potentially receive Portland cement $(\mathrm{STCC}=32411)$ are road construction firms ( $\mathrm{SIC}=1610-1619)$, concrete brick and block manufacturers ( $\mathrm{SIC}=3271)$, ready-mix concrete manufacturers $(\mathrm{SIC}=3273)$, and wholesalers of brick, stone, and related materials $(\mathrm{SIC}=5032) \cdot{ }^{31,32}$ For paper and paperboard manufacturers, I look for shipments in the Commodity Flow Survey for which the commodity code is that of paperboard ( $\mathrm{STCC}=26311$ in 1993, $\mathrm{SCTG}=27319-27320$ in 1997), which are also sent to zip codes that contain establishments in either the corrugated and solid fiber boxes ( $\mathrm{SIC}=2653$ ) industry or the folding paperboard boxes ( $\mathrm{SIC}=2657$ ) industry. Finally, I drop shipments for which the unit price is greater than four times, or less than one-fourth, the average for the industry-year.

For within-firm shipments, surveyed establishments do not report the actual market value of the transaction. Instead, the establishments are asked to estimate what the value of the shipment would have been had it been sold to some other firm. Since it is unclear what these values actually represent, I remove downstream establishments who receive a substantial fraction, $15 \%$ or more, of the relevant input from other plants from the same

\footnotetext{
${ }^{29}$ Atalay, Hortaçsu, and Syverson (2013) make the same assumption. This assumption is motivated by the finding that establishment $h$ is much more likely to ship to zip codes that contain an establishment from the same firm. The results of the current section are not sensitive to this assumption.

${ }^{30}$ Assigning all potential recipients, $i$, to be downstream of plant $h$ likely overcounts the number of buyersupplier relationships. In an unreported robustness check, I reproduce the analysis of Section 4.2, weighing observations by the inverse of the number of potential recipients in the destination zip code. I find that the results are essentially unchanged.

${ }^{31}$ The commodity code used in the 1993 Commodity Flow Survey is the Standard Transportation Commodity Code (STCC). A list of STCC codes can be found in pages 117 to 167 of "Reference Guide for the 2008 Surface Transportation Board Carload Waybill Sample," published by Railinc. Since 1997, the Commodity Flow Survey has used the Standard Classification of Transported Goods (SCTG) classification of commodity codes. Documentation related to SCTG codes can be found on the Census web page.

${ }^{32}$ Productivity data for cement and ready-mix concrete manufacturers are unavailable in 1997 . So, for cement and concrete manufacturers, I only look at buyer-supplier relationships in the 1993 Commodity Flow Survey.
} 
firm..$^{33}$

\subsection{Sources of Materials Price Dispersion}

The purpose of this subsection is to describe and assess the quantitative importance of the three potential sources of materials price variation.

I begin with some notation. Let $\chi_{\text {hit }}$ denote the total mass (in thousands of pounds) of shipments sent by plant $h$ to plant $i$ in year $t$, and let $\omega_{h i t}$ denote the total value (in thousands of real dollars) of shipments sent by plant $h$ to plant $i$ in year $t$. Then, the free on board (f.o.b.) $)^{34}$ price that plant $h$ charges plant $i$ is simply the ratio of the value to the price:

$$
P_{\text {hit }}^{C F S} \equiv \frac{\omega_{\text {hit }}}{\chi_{\text {hit }}}
$$

The "CFS" superscript denotes prices computed using the Commodity Flow Survey data (as opposed to the prices that are computed in Section 3, using data from the Census of Manufacturers). ${ }^{35}$

For each downstream plant, $i$, input prices are defined by taking the value-weighted average over all plants, $h$, that I observe $i$ purchasing from:

$$
P_{i t}^{i n, C F S} \equiv \frac{\sum_{h \in \Gamma(i)} \omega_{h i t} \cdot P_{h i t}^{C F S}}{\sum_{h \in \Gamma(i)} \omega_{h i t}}
$$

In Equation 18, and throughout the remainder of this section, $\Gamma(i)$ refers to the suppliers of plant $i$, excluding the establishments that are in the same firm as plant $i$. Note that, because it does not include freight charges, $P_{i t}^{i n, C F S}$ will be less than what plants pay for their intermediate inputs. I define a second plant-level input price, which includes freight

\footnotetext{
${ }^{33}$ While varying the $15 \%$ cutoff down to $0 \%$ or up to $25 \%$ does not affect this section's results, the relationship between input prices and supplier productivity begins to disappear once the cutoff exceeds 25 or $30 \%$.

Bernard, Jensen, and Schott (2006) show that reported prices on cross-border shipments, for which the sender and receiver are part of the same firm, are manipulated to take advantage of the different tax policies of the destination and source countries. Even though such an incentive to mis-report does not exist in the Commodity Flow Survey data, I argue that one should not put too much weight on input prices of the plants that buy a substantial fraction of their inputs from within the firm.

${ }^{34}$ Unlike the (cost, insurance, and freight) c.i.f. price, the f.o.b. price does not include freight or insurance charges.

${ }^{35}$ The Commodity Flow Survey has, up to now, been an unexploited source of data on plants' output prices. With this in mind, I compare plants' output prices, derived from the Commodity Flow Survey to the prices derived from the better-known Census of Manufacturers. For the 66 cement manufacturers in this section's sample, the correlation between $p_{h}^{\text {out }, C F S}$ and $p_{h}^{\text {out }}$ is $39 \%$. For the 162 paperboard manufacturers, the correlation between the two plant-level output prices is $60 \%$.
} 
charges:

$$
\tilde{P}_{i t}^{i n, C F S} \equiv \frac{\sum_{h \in \Gamma(i)} \omega_{h i t} \cdot\left(P_{h i t}^{C F S}+\tau_{h i t}\right)}{\sum_{h \in \Gamma(i)} \omega_{h i t}}
$$

I estimate transportation costs, $\tau_{\text {hit }}$, from the mileage of the shipment and the mode of transport. ${ }^{36,37}$

Similar to the analysis of Section 3, all plant-level statistics are stated as the percent deviation relative to the average value for the industry-year. Again, these deviations are written using lower-case letters.

\section{Geography}

Geography is the first of the three sources of materials price variation. As discussed in Section 3.3, of the 10 industries in the benchmark sample, concrete is the industry with the strongest spatial correlation in materials prices, while the corrugated box industry displays relatively weak spatial correlation. Cement prices tend to be lower in areas with an abundance of limestone, namely in the Appalachian and Great Lakes regions. ${ }^{38}$ To assess the relationship between concrete plants' materials prices and their proximity to limestone production, I regress - for the 3708 concrete plant-year observations in the benchmark sample $-p_{i j t}^{i n}$ against nearby employment in the limestone industry. The coefficient estimates given in the final column of Table 9 imply that the materials price of concrete plants is roughly $10 \%$ higher for plants that are in the 75 th percentile of the limestone proximity index, relative to plants in the 25 th percentile.

\section{Suppliers' Marginal Costs}

Even within geographical areas, there is heterogeneity in plants' suppliers' marginal costs. For any concrete or corrugated box manufacturer, $i$, that is identified by the algorithm

\footnotetext{
${ }^{36}$ The Bureau of Transportation Statistics collects information on ton-mile freight charges for shipments sent along different transport modes; see U.S. Department of Transportation (2009). Since the Commodity Flow Survey contains information on the weight of each shipment, as well as the distance that the shipment traveled, it is straightforward to estimate the shipment freight charge.

${ }^{37}$ For the corrugated box manufacturing industry, I relate $\tilde{p}_{i t}^{i n, C F S}$ and $p_{i t}^{i n}$. (Remember that $p_{i t}^{i n}$ cannot be computed in 1992 or 1997 for ready-mix concrete manufacturers.) The strength of this relationship, between the materials prices computed from the two data sources, indicates the success (or lack thereof) of the imputation procedure outlined in Section 4.1. The correlation between $\tilde{p}_{i t}^{i n, C F S}$ and $p_{i t}^{i n}$ is $22 \%$, meaning that I am mismeasuring many buyer-supplier relationships, but that the imputation algorithm yields a viable dataset.

${ }^{38}$ In 1997, 48\% of limestone shipment value originated from eight states-Alabama, Kentucky, Illinois, Indiana, Ohio, Pennsylvania, Tennessee, and West Virginia - which represent roughly $24 \%$ of the U.S. population. See http://www.census.gov/prod/ec97/97n2123b.pdf for the state-by-state data on limestone production.
} 


\begin{tabular}{lccc}
\hline Nearby limestone & $-0.043^{*}$ & $-0.138^{*}$ & $-0.232^{*}$ \\
employment & $(0.005)$ & $(0.012)$ & $(0.028)$ \\
(Nearby limestone $^{\text {employment) }}$ & & $0.047^{*}$ & $0.159^{*}$ \\
(Nearby limestone $^{2}$ & & $(0.005)$ & $(0.028)$ \\
employment) & & & $-0.031^{*}$ \\
Adjusted $R^{2}$ & 0.034 & 0.056 & 0.060 \\
\hline
\end{tabular}

Table 9: Relationship between materials prices and nearby limestone production. Notes: Observations are revenue weighted. Stars indicate significance at the $5 \%$ level. N=3708.

outlined in Section 4.1, I compute average supplier productivity, $\overline{T F P Q}_{i t}$, as follows:

$$
\overline{T F P Q}_{i t} \equiv \frac{\sum_{h \in \Gamma(i)} \omega_{h i t} \cdot T F P Q_{h t}}{\sum_{h \in \Gamma(i)} \omega_{h i t}} .
$$

The dispersion of $\overline{t f p q}_{i t}$ (the percent deviation of $\overline{T F P Q}_{i t}$ from its industry-year average) is substantial. For plants in the ready-mix-concrete (box-making) industry, the standard deviation of $\overline{t f p q}_{i t}$ is $41 \%$ (26\%). After including year by geographic division fixed effects, the standard deviation of $\overline{t f p q}_{i t}$ is $36 \%$ for the ready-mix concrete industry, and $25 \%$ for the corrugated box industry. ${ }^{39}$

\section{Within-Supplier Price Differences}

A third explanation for price variation lies in differences in the relative bargaining power of the suppliers and buyers of any given material input, yielding variation in the prices that suppliers charge, for the same good, across destinations. Define a supplier's average output price, $P_{h t}^{\text {out }, C F S}$, as a value-weighted average of the prices that it charges in its Commodity Flow Survey shipments. For each buyer-supplier relationship, I define the within-supplier price deviation, $\psi_{\text {hit }}$, as:

$$
\psi_{h i t} \equiv \log \left(\frac{P_{h i t}^{C F S}}{P_{h t}^{\text {out }, C F S}}\right),
$$

where $\psi_{h i t}$ is the price that $i$ pays for $h$ 's output, relative to the other plants that buy intermediate inputs from $h ; \psi_{h i t}$ is positive provided plant $i$ purchases its material inputs from $h$ at a higher price than $P_{h t}^{\text {out }, C F S}$, the average output price of supplier, $h$.

Figure 1 decomposes the price distribution into two separate components. Any buyer-supplier-specific price, $p_{h i t}^{C F S}$, is the sum of the supplier's average output prices, $p_{h t}^{\text {out }, C F S}$, and the within-supplier price deviation, $\psi_{h i t}$. The price, $p_{h i t}^{C F S}$, that a supplier charges a buyer

\footnotetext{
${ }^{39}$ There are nine Census-defined divisions within the United States. See http://www.census.gov/geo/www/us_regdiv.pdf for a correspondence between states and divisions.
} 


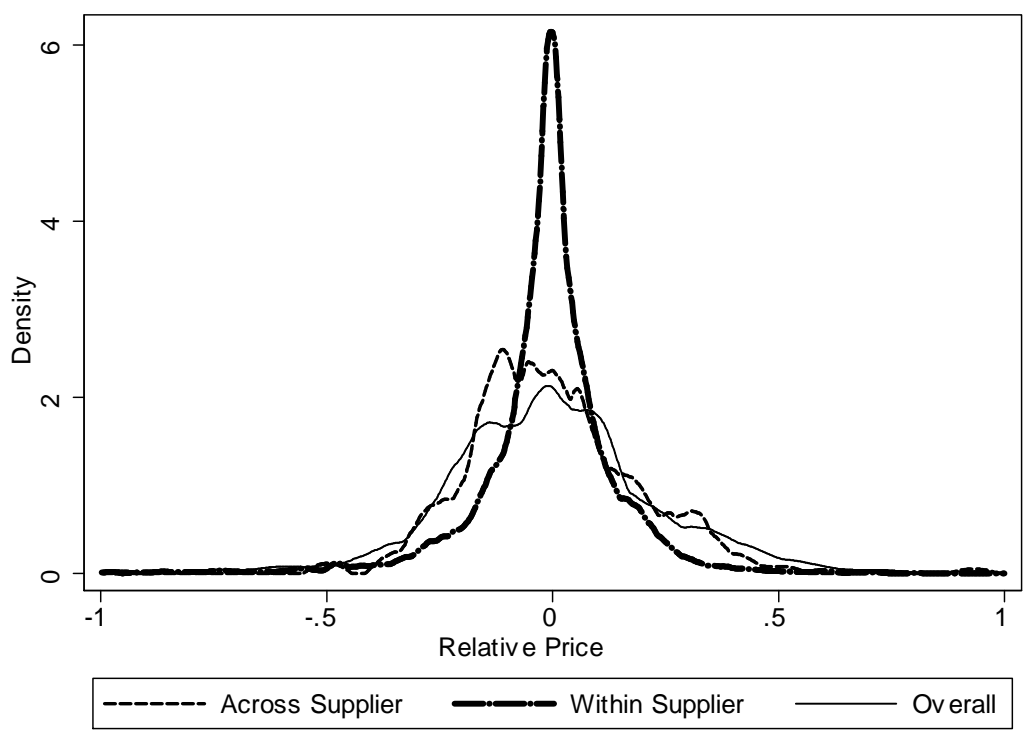

Figure 1: Value-weighted price distributions.

Notes: The sample includes all shipments sent by the cement and paperboard manufacturers that comprised the sample of the regression defined by Equation 23.

for intermediate inputs can be, mechanically, high for one of two reasons: either the supplier has a high average price, $p_{h t}^{\text {out }, C F S}$, or the supplier charges $i$ a higher price than its other customers (i.e., $\psi_{\text {hit }}$ is large). ${ }^{40}$ For my sample of cement and paperboard manufacturers, the distributions of $p_{\text {hit }}^{C F S}, \psi_{\text {hit }}$, and $p_{h t}^{\text {out }, C F S}$ are depicted in Figure 1 . The standard deviation of $p_{\text {hit }}^{C F S}$ is $25 \%$, larger than the standard deviation of suppliers' average output prices $\left(S D\left(p_{h t}^{\text {out }, C F S}\right)=19 \%\right)$, and fifty percent larger than the standard deviation of the within-supplier deviations $\left(S D\left(\psi_{\text {hit }}\right)=16 \%\right){ }^{41}$

The average within-supplier price deviation, $\psi_{i t}$, measures the extent to which plant $i$ pays its supplier a higher materials price than the other customers of its suppliers. It is a weighted average, over $i$ 's suppliers, of the $\psi_{\text {hit }}$ :

$$
\psi_{i t} \equiv \frac{\sum_{h \in \Gamma(i)} \omega_{h i t} \cdot \psi_{h i t}}{\sum_{h \in \Gamma(i)} \omega_{h i t}}=\frac{\sum_{h \in \Gamma(i)} \omega_{h i t} \cdot\left(p_{h i t}-p_{h t}^{\text {out }, C F S}\right)}{\sum_{h \in \Gamma(i)} \omega_{h i t}}
$$

\footnotetext{
${ }^{40}$ Price discriminatory behavior, which would result from differences in buyers' and suppliers' bargaining positions, is a first explanation for these within-supplier price differences. In addition, some of the withinsupplier variation in materials prices may potentially be due to the time at which plant $i$ receives its shipments from plant $h$. In Web Appendix A.11, I argue that, at least for this small sample of concrete and box manufacturers, the timing of shipments is not a primary source of materials price variation.

${ }^{41}$ Figure 1 looks similar, whether one uses the sample of cement manufacturers, the sample of paperboard manufacturers, or the pooled sample of paperboard and cement manufacturers. See Web Appendix A.12.
} 


\begin{tabular}{lccccccccc}
\hline Sample & \multicolumn{3}{c}{ Boxes } & \multicolumn{3}{c}{ Concrete } & \multicolumn{3}{c}{ Pooled } \\
\hline$\overline{t f p q}_{i t}$ & $-0.267^{*}$ & $-0.257^{*}$ & $-0.233^{*}$ & $-0.201^{*}$ & -0.210 & -0.146 & $-0.253^{*}$ & $-0.243^{*}$ & $-0.212^{*}$ \\
& $(0.059)$ & $(0.057)$ & $(0.056)$ & $(0.092)$ & $(0.110)$ & $(0.105)$ & $(0.050)$ & $(0.048)$ & $(0.047)$ \\
$\psi_{i t}$ & & & $0.340^{*}$ & & & $0.691^{*}$ & & & $0.406^{*}$ \\
$N$ & & & $(0.111)$ & & & $(0.165)$ & & & $(0.118)$ \\
Adjusted $R^{2}$ & 190 & 190 & 190 & 131 & 131 & 131 & 321 & 321 & 321 \\
Division F.E.? & 0.129 & 0.133 & 0.223 & 0.046 & 0.091 & 0.511 & 0.107 & 0.117 & 0.263 \\
& No & Yes & Yes & No & Yes & Yes & No & Yes & Yes \\
\hline
\end{tabular}

Table 10: Regression results.

Notes: This table presents coefficient estimates and robust standard errors, from the regressions defined by Equation 23. The dependent variable in this regression is $\tilde{p}_{i t}^{i n, C F S}$. Observations are assigned weights according to the revenues of plant $i$. Stars indicate significance at the $5 \%$ level.

\section{Regression Results}

Using these definitions, I can now compare the price that a plant pays for its material inputs to differences in geography (summarized by division fixed effects), differences in suppliers' marginal costs, and within-supplier price differences. ${ }^{42}$

$$
\tilde{p}_{i t}^{i n, C F S}=\beta_{\text {division }}+\beta_{1} \cdot \overline{t f p q}_{i t}+\beta_{2} \cdot \psi_{i t}+\varepsilon_{i t}
$$

The results are presented in Table 10. A $10 \%$ increase in the marginal cost of plants' suppliers corresponds to a $2.0 \%$ to $2.5 \%$ increase in plants' materials prices. The estimated effect of supplier productivity on materials prices is somewhat stronger for boxes than it is for ready-mix concrete. Including fixed effects for the geographic region of the downstream plant has almost no effect on the estimate of $\beta_{1}{ }^{43}$ Finally, the coefficient estimate, $\beta_{2}$, on the average within-supplier deviation term is positive and significant. Note that, a mechanical relationship between $\psi_{i t}$ and $\tilde{p}_{i t}^{i n, C F S}$ exists, as higher-than-average-priced shipments will generate a large value for $\tilde{p}_{i t}^{i n, C F S}$ (see Equation 19) and a large value of $\psi_{i t}$ (see Equation 22). Measurement error in $P_{h i t}^{C F S}$, for example, will skew the coefficient estimate of $\beta_{2}$ towards 1 .

Each cell in Table 11 presents the unexplained variation - measured as the (revenueweighted) standard deviation of the residuals - when $\tilde{p}_{i t}^{i n, C F S}$ is regressed on different combinations of the right-hand side variables of Equation 23. Comparing the first and second columns of Table 11, I calculate that the inclusion of division fixed effects reduces the unexplained variation of materials prices by approximately $2 \%$. The inclusion of suppliers'

\footnotetext{
${ }^{42} \mathrm{Using} p_{i t}^{i n, C F S}$ instead of $\tilde{p}_{i t}^{i n, C F S}$ as the dependent variable of the regression corresponding to Equation 23 generates a similar estimate of $\beta_{1}$.

${ }^{43}$ It is possible that division fixed effects are too coarse to sufficiently control for the geographic variation in materials prices. Web Appendix A.13 presents evidence that this is not the case.
} 


\begin{tabular}{|c|c|c|c|c|c|c|c|c|c|}
\hline & $\begin{array}{l}\text { Include Division } \\
\text { Fixed Effects? }\end{array}$ & No & Yes & No & Yes & No & Yes & No & Yes \\
\hline & Include $\overline{t f p q}_{i t}$ ? & No & No & Yes & Yes & No & No & Yes & Yes \\
\hline Sample & $\begin{array}{l}\text { Include } \psi_{i t} ? \\
\text { Sample Size }\end{array}$ & No & No & No & No & Yes & Yes & Yes & Yes \\
\hline Boxes & 190 & 0.187 & 0.180 & $0.174^{*}$ & $0.170^{*}$ & $0.175^{*}$ & $0.169^{*}$ & $0.164^{*}$ & $0.160^{*}$ \\
\hline Concrete & 131 & 0.359 & 0.338 & 0.349 & 0.330 & $0.268^{*}$ & $0.247^{*}$ & $0.262^{*}$ & $0.241^{*}$ \\
\hline Pooled & 321 & 0.209 & 0.204 & $0.197^{*}$ & $0.194^{*}$ & $0.189^{*}$ & $0.185^{*}$ & $0.180 *$ & $0.177^{*}$ \\
\hline
\end{tabular}

Table 11: Unexplained materials price variation.

Notes: Each cell gives the real-revenue-weighted standard deviation of the residuals in a particular regression; the full specification is given in Equation 23. Across the columns of the table, different combinations of independent variables are included in the regressions. Stars indicate that the decline in dispersion is significantly more than the decline that would occur from simply including "fake" random variables on the right-hand side of Equation 23. See Web Appendix C for details.

productivities reduces the unexplained variation by approximately $6 \%$, while the two sets of variables jointly reduce the unexplained price variation by $7 \%$. Finally, the full combination of right-hand-side variables - including the average within-supplier deviation - reduces the unexplained variation of $\tilde{p}_{i t}^{i n, C F S}$ by $15 \%$. To summarize, both within-supplier and betweensupplier explanatory factors are significant and quantitatively important when accounting for the dispersion in downstream plants' materials prices. ${ }^{44}$ These findings indicate that while purely geographical considerations - such as spatial differences in resource abundance drive some of the differences in materials prices, the factor market's competitive environment is also of primary significance.

\subsection{Persistence of Relationships}

Buyer-supplier relationships are persistent across time, suggesting that there is some force that inhibits intermediate inputs purchasers from switching suppliers. Whether this inhibiting force reflects some extra profitability that is conferred by repeated interaction, or some idiosyncratic match-specific productivity, it prevents all buyers from switching to the lowest-cost intermediate goods suppliers.

To provide some empirical evidence for the persistence of buyer-supplier relationships, I explore the shipments sent by cement and paperboard manufacturers in the 1993 and 1997 Commodity Flow Surveys. As before, the Commodity Flow Survey does not iden-

\footnotetext{
${ }^{44}$ Regarding the statistical significance of the results, note that any set of variables - for example, a random variable drawn from a standard normal distribution, or a set of 12 dummy variables that sum up to $1-$ will necessarily explain some positive fraction of the variation in $\tilde{p}_{i}^{i n, C F S}$. In Web Appendix C, I test whether the decline in dispersion is significantly greater than what would be expected from including different combinations of "fake" random variables on the right-hand side of Equation 23.
} 


\begin{tabular}{|c|c|c|c|c|c|c|}
\hline \multirow{3}{*}{$\begin{aligned} \text { Sample } \\
\text { Log Mileage }\end{aligned}$} & Cement & Cement & Cement & Paperboard & Paperboard & Paperboard \\
\hline & -2.835 & -2.594 & -2.593 & -1.025 & -0.867 & -0.881 \\
\hline & $(0.050)$ & $(0.050)$ & $(0.051)$ & $(0.024)$ & 0.026 & $(0.026)$ \\
\hline Did the plant sell to & & 2.075 & 2.009 & & 2.988 & 2.661 \\
\hline the zip code in $1993 ?$ & & $(0.105)$ & $(0.105)$ & & $(0.067)$ & $(0.069)$ \\
\hline$N$ & 106,795 & 106,795 & 106,795 & 75,360 & 75,360 & 75,360 \\
\hline Number of zip codes & 2015 & 2015 & 2015 & 1256 & 1256 & 1256 \\
\hline Number of plants & 53 & 53 & 53 & 60 & 60 & 60 \\
\hline Pseudo- $R^{2}$ & 0.687 & 0.713 & 0.718 & 0.148 & 0.257 & 0.290 \\
\hline $\begin{array}{l}\text { Unconditional probability } \\
\text { of shipping to zip code } z\end{array}$ & 0.021 & 0.021 & 0.021 & 0.030 & 0.030 & 0.030 \\
\hline $\begin{array}{l}\text { Include control for } \\
\text { firm presence in } z \text { ? }\end{array}$ & No & No & Yes & No & No & Yes \\
\hline
\end{tabular}

Table 12: Persistence of buyer-supplier relationships.

Notes: This table presents coefficient estimates and standard errors, from the regression defined by Equation 24. The sample is comprised of cement and paperboard plants that were included in the sample of Regression 23. For a zip code to be in the sample, at least one plant in the sample must have shipped to the zip code in $1997 . .^{45}$

tify the downstream buyer. Instead, I proxy for the identity of the downstream buyer using the destination zip code. I run a conditional logit regression, described by Equation 24; the dependent variable equals 1 if the cement/paperboard plant, $i$, ships to zip code, $z$, in 1997. The explanatory variable of interest is an indicator, which equals 1 if the plant shipped to the zip code in 1993. Destination zip code-level fixed effects, supplier fixed effects, and the $\log$ distance between $i$ and $z$ are additional explanatory variables.

$$
\begin{aligned}
\mathbb{I}\{i \rightarrow z \text { in } 1997\} & =\beta_{z}+\beta_{i}+\beta_{3} \cdot \log (\text { distance } i \rightarrow z)+\beta_{4} \cdot \mathbb{I}\{i \rightarrow z \text { in } 1993\} \\
& +\beta_{5} \cdot \mathbb{I}\{\text { plant of i's firm is located in } z \text { in } 1997\}+\varepsilon_{i z}
\end{aligned}
$$

The results are presented in Table 12. Both cement and paperboard suppliers' decisions on which destinations to ship to are persistent across time. If plant $i$ sells to zip code $z$ in 1993, the probability that $i$ will sell to $z$ in 1997 is much larger, approximately 6 to 8 times larger for cement manufacturers, and 10 to 14 times larger for paperboard manufacturers.

\footnotetext{
${ }^{45}$ In addition, I restrict the sample to establishments that were sampled in both the 1993 and 1997 Commodity Flow Surveys. Secondly, in order to comply with Census disclosure rules, I restrict the sample to plants that are members of firms, $f$, such that the following three criteria hold: a) there exists at least one $i, z$ pair for which plant $i$ (owned by $f$ ) shipped to $z$ in 1993, but not in 1997; b) there exists at least one $i, z$ pair for which plant $i$ shipped to $z$ in 1997, but not in 1993; and c) there exists at least one $i, z$ pair for which $i$ shipped to $z$ in both 1993 and 1997. The coefficient estimates are similar when the sample is constructed without this second restriction.
} 
There are two distinct interpretations of the positive estimate on, $\beta_{4}$, the coefficient on the persistence of buyer-supplier relationships (see, for example, Dubé, Hitsch, and Rossi 2010). In the first interpretation, an establishment's profitability of working with a counterparty increases from having transacted with that counterparty in the past. Kellogg (2011), for instance, documents that oil production companies and drillers become more productive as they gain experience working with one another. According to the second interpretation, some establishments happen to find it more profitable to work with certain counterparties for idiosyncratic reasons, other than geographic proximity. The estimate of the persistence term, $\beta_{4}$, will be positive provided these idiosyncratic factors display some persistence. Unfortunately, the data that I have at hand do not permit me to distinguish between these two interpretations. Either interpretation, however, is consistent with downstream establishments that decide to remain matched with high marginal cost suppliers.

\section{Conclusion}

In this paper, I have studied the consequences and sources of materials price dispersion. Variation in materials prices explains a substantial fraction of the variation in plants' marginal costs, revenue total factor productivities, and probabilities of survival. Moreover, one reason why some plants have low materials prices is that they have access to suppliers with low marginal costs.

The paper's results suggest that establishments' survival and growth prospects are directly related to those of their customers and/or suppliers. In future work, I hope to investigate the relationship between establishments' growth and the growth rates of their counterparties. Such an investigation will be an important building block in understanding the propensity with which shocks to a small set of firms have the potential to cascade throughout the economy and produce aggregate fluctuations.

\section{A Robustness Checks and Other Calculations}

\section{A.1 Industries with Heterogeneous Quality Outputs}

In this subsection, I reproduce the empirical analysis of Sections 3.1, 3.2, and 3.3 for a set of industries that display substantial output quality variation. The four industries that I choose for this exercise are cucumber pickles, sausages, softwood cut stock, and wine. Details on the construction of the sample can be found in Web Appendix B.2.

Correlations among plant-level characteristics are presented in Table 13. Compared 


\begin{tabular}{lccccc}
\hline & $p^{\text {in }}$ & $p^{\text {out }}$ & $t f p q$ & $\phi$ & $t f p r$ \\
\hline$p^{\text {out }}$ & $0.284^{*}$ & & & & \\
$t f p q$ & $-0.273^{*}$ & $-0.808^{*}$ & & & \\
$\phi$ & $0.254^{*}$ & $-0.659^{*}$ & $0.858^{*}$ & & \\
tfpr & 0.024 & $0.329^{*}$ & $0.305^{*}$ & $0.290^{*}$ & \\
Std. Dev. & 0.318 & 0.385 & 0.380 & 0.380 & 0.237 \\
\hline
\end{tabular}

Table 13: Correlations and standard deviations of plant-level characteristics.

Notes: Observations are revenue weighted. Stars indicate that the correlation is significantly different from 0 , at the $5 \%$ level (see Web Appendix C for details). $\mathrm{N}=1256$.

\begin{tabular}{lcccccccccc}
\hline & \multicolumn{1}{c}{ Dispersion of $t f p q$} & \multicolumn{4}{c}{ Dispersion of $\phi$} & \multicolumn{7}{c}{ Percent Decline } \\
\hline \multicolumn{1}{c}{ Sample } & $90 / 10$ & $75 / 25$ & SD & $90 / 10$ & $75 / 25$ & SD & $90 / 10$ & $75 / 25$ & SD & $N$ \\
\hline Pickles & 0.891 & 0.446 & 0.344 & 0.881 & 0.412 & 0.339 & $1.2 \%$ & $8.6 \%$ & $1.3 \%$ & 145 \\
Sausages & 0.727 & 0.399 & 0.295 & 0.747 & 0.366 & 0.301 & $-2.7 \%$ & $9.5 \%$ & $-2.0 \%$ & 621 \\
Softwood & 1.571 & 0.818 & 0.547 & 1.316 & 0.697 & 0.477 & $21.4 \%^{*}$ & $18.9 \%$ & $16.0 \%^{*}$ & 160 \\
Wine & 1.314 & 0.696 & 0.479 & 1.268 & 0.726 & 0.481 & $3.6 \%$ & $-4.0 \%$ & $-0.5 \%$ & 330 \\
Pooled & 0.948 & 0.494 & 0.380 & 0.977 & 0.486 & 0.380 & $-2.9 \%$ & $1.7 \%$ & $0.0 \%$ & 1256 \\
\hline
\end{tabular}

Table 14: Dispersion of $t f p q$ and $\phi$.

Notes: Observations are revenue weighted. Stars indicate that the difference between $t f p q$ and $\phi$ is statistically significant, at the $5 \%$ level (see Web Appendix C for details).

to the benchmark sample, the standard deviations of most plant-level characteristics are larger, while the correlations among the different productivity measures are, in general, weaker. While the correlation between $t f p r$ and $p^{i n}$ is negative $(-0.232)$ and significant in the benchmark sample, in the Quality Variation sample there is essentially no relationship between input prices and revenue productivity. Within the Quality Variation sample, high materials prices reflect high-quality inputs, which in turn lead to greater profitability. (There is still the countervailing relationship - as for the benchmark sample - where high materials prices reflect unfavorable factor market conditions, potentially lowering profitability.)

The dispersions of $t f p q$ and $\phi$ are given in Table 14. For the pooled sample, the dispersions of the two distributions are essentially the same. Looking across the four industries, there is a significant decline in productivity dispersion for one of the industries, softwood cut stock, and no difference for the other three industries.

In Table 15, I present regression results, in which I regress plants' materials prices against the materials prices of nearby plants (those within 250 miles, in the same industryyear). The fraction of materials price variation that is explained by neighbors' average materials prices is essentially 0 for each of the four industries in the Quality Variation sample.

In summation, output quality variation has the potential to severely attenuate the difference between the dispersions of $\phi$ and $t f p q$. To the extent that any quality variation 


\begin{tabular}{lccc}
\hline \multicolumn{1}{c}{ Sample } & $\beta$ & s.e. & Adjusted $R^{2}$ \\
\hline Pickles & 0.124 & 0.130 & -0.001 \\
Sausages & 0.038 & 0.075 & -0.001 \\
Softwood & -0.165 & 0.137 & 0.003 \\
Wine & -0.456 & 0.195 & 0.013 \\
Pooled & -0.017 & 0.064 & -0.001 \\
\hline
\end{tabular}

Table 15: Spatial correlation of materials prices.

Notes: The dependent variable is $p_{i j t}^{i n}$, and the independent variable is the (revenue-weighted) average of the $p_{i^{\prime} j t}^{i n}$ for the plants that are within a 250-mile radius of plant $i$ in industry $j$ and year $t$. Observations are revenue weighted.

exists in the benchmark sample, the difference between the dispersions of $\phi$ and $t f p q$, as reported in Table 3, may be downwardly biased.

\section{A.2 Variation in Input Quality}

One of the main presumptions of the empirical analysis is that variation in input quality is not an important source of variation of input prices. I have chosen industries to try to minimize the role of input quality differentiation. There is one specific industry, readymix concrete, for which there is reason to suspect that input quality differences could be contaminating some of the results. In this subsection, I explain why input quality varies across plants, and then determine how big of an effect input quality variation has on the observed relationships between input prices and different productivity measures.

Portland cement, the main intermediate input used in the production of ready-mix concrete, comes in four types, labeled type I, II, III, or IV. ${ }^{46}$ Type-I and II cement account for over $90 \%$ of the expenditures on cement, with the majority of sales coming from typeI cement (U.S. Department of Interior 1989). In areas where the soil has high sulfate concentrations, type-II cement may be preferable to the less expensive type-I cement, since ready-mix concrete produced using type-I cement is susceptible to sulfate attack (cracking or loss of strength in the presence of sulfate). Since high sulfate concentrations exist only in the soil of parts of the western third of the United States, one should observe type-I and type-II cement consumed in the western United States, and only type-I cement consumed in the remainder of the United States. ${ }^{47}$

\footnotetext{
${ }^{46}$ The standards for the different types of Portland cement are set by the American Society for Testing and Materials (ASTM). See the ASTM web page for more information on the distinguishing features of different types of Portland cement: http://www.astm.org/Standards/C150.htm .

${ }^{47}$ Cement type is not recorded in the Census of Manufacturers materials file. I confirm, using the Census of Manufacturers production file, that only type-I cement is produced by plants in the eastern two-thirds of the United States, while both types I and II are produced in the western U.S.
} 


\begin{tabular}{ccccccccc}
\hline Sample & $p^{\text {in }}, t f p q$ & $p^{\text {in }}, \phi$ & $p^{\text {in }}, p^{\text {out }}$ & $p^{\text {in }}, t f p r$ & $\phi, t f p q$ & $t f p q, t f p r$ & $t f p q, p^{\text {out }}$ & $N$ \\
\hline Entire U.S. & $-0.306^{*}$ & $0.120^{*}$ & $0.276^{*}$ & $-0.127^{*}$ & $0.908^{*}$ & $0.741^{*}$ & $-0.476^{*}$ & 3708 \\
Divisions 1-7 & $-0.341^{*}$ & $0.089^{*}$ & $0.251^{*}$ & $-0.180^{*}$ & $0.906^{*}$ & $0.750^{*}$ & $-0.430^{*}$ & 3049 \\
Divisions 8-9 & $-0.351^{*}$ & 0.066 & $0.360^{*}$ & -0.105 & $0.911^{*}$ & $0.688^{*}$ & $-0.597^{*}$ & 659 \\
\hline
\end{tabular}

Table 16: Correlations among plant-level characteristics.

Notes: Observations are revenue weighted. Stars indicate that the correlation is significantly different from 0 , at the $5 \%$ level.

\begin{tabular}{lcccccccccc}
\hline & \multicolumn{4}{c}{ Dispersion of $t f p q$} & \multicolumn{3}{c}{ Dispersion of $\phi$} & \multicolumn{1}{c}{ Percent Decline } \\
\multicolumn{1}{c}{ Sample } & $90 / 10$ & $75 / 25$ & SD & $90 / 10$ & $75 / 25$ & SD & $90 / 10$ & $75 / 25$ & SD & $N$ \\
\hline Entire U.S. & 0.521 & 0.251 & 0.224 & 0.486 & 0.236 & 0.215 & $7.4 \%^{*}$ & $6.6 \%^{*}$ & $4.4 \%^{*}$ & 3708 \\
Divisions 1-7 & 0.486 & 0.238 & 0.211 & 0.439 & 0.222 & 0.199 & $11.3 \%^{*}$ & $7.7 \%^{*}$ & $6.2 \%^{*}$ & 3049 \\
Divisions 8-9 & 0.611 & 0.296 & 0.255 & 0.570 & 0.253 & 0.239 & $7.4 \%$ & $18.3 \%^{*}$ & $6.9 \%^{*}$ & 659 \\
\hline
\end{tabular}

Table 17: Dispersion of $t f p q$ and $\phi$.

Notes: Stars indicate that the difference between $t f p q$ and $\phi$ is statistically significant, at the $5 \%$ level.

Given this geographic difference in soil composition, I split the sample of ready-mix concrete plants into two subsamples: plants residing in Census divisions 1-7, and plants located in Census divisions 8-9. ${ }^{48}$ The dispersion of $p^{i n}$ is larger in divisions 8-9 (20.0\%, versus $17.0 \%$ for divisions 1-7), as some ready-mix concrete plants purchase the low price type-I cement, while others must purchase the high price type-II cement. In contrast, in the eastern United States, virtually all ready-mix concrete plants purchase type-I cement, leading to a more compressed $p^{i n}$ distribution. For both subsamples, $t f p q$ and $p^{i n}$ are inversely related to one another, with the negative relationship between $t f p q$ and $p^{i n}$ somewhat stronger in the eastern United States; see Table 16. These geographic differences are consistent with greater cement quality variation in the western United States.

In Table 17, I compute the dispersion of $t f p q$ and $\phi$ for the ready-mix concrete subsamples. The decline in dispersion is larger for each of the two subsamples than it is for the pooled sample of 3708 ready-mix concrete plants.

In Table 18, I assess the spatial correlation of materials prices, separately for plants in the eastern and western United States. Materials prices are strongly spatially correlated, within each of the two parts of the U.S. Thus, it does not seem as if the spatial correlation of cement prices is primarily due to higher-than-average input quality in the western U.S.

In summation, there is almost no variation in the quality of cement purchased by ready-mix concrete plants in the eastern two-thirds of the United States. For this subsample, the difference between the standard deviation of $t f p q$ and the standard deviation of $\phi$ is 2 to

\footnotetext{
${ }^{48}$ Census division 8 is made up of Arizona, Colorado, Idaho, Montana, Nevada, New Mexico, Utah, and Wyoming, while Census division 9 includes Alaska, California, Hawaii, Oregon, and Washington.
} 


\begin{tabular}{lccc}
\hline \multicolumn{1}{c}{ Sample } & $\beta$ & s.e. & Adjusted $R^{2}$ \\
\hline Entire U.S. & 0.913 & 0.028 & 0.222 \\
Divisions 1-7 & 0.936 & 0.033 & 0.210 \\
Divisions 8-9 & 0.812 & 0.068 & 0.177 \\
\hline
\end{tabular}

Table 18: Spatial correlation of materials prices.

Notes: The dependent variable is $p_{i j t}^{i n}$, and the independent variable is the (revenue-weighted) average of the $p_{i^{\prime} j t}^{i n}$ for the plants that are within a 250-mile radius of plant $i$ in industry $j$ and year $t$. Observations are revenue weighted.

3 percentage points larger than the differences that are reported in Table 3. So, a moderate amount of materials quality variation would probably cause me to somewhat underreport the fraction of productivity dispersion that is due to differences in factor market conditions.

\section{References}

Ackerberg, Daniel A., Kevin Caves, and Garth Frazer (2006). "Structural Identification of Production Functions." Working paper, University of Toronto.

Atalay, Enghin, Ali Hortaçsu, and Chad Syverson (2013). "Vertical Integration and Input Flows." Working paper, University of Chicago.

Baily, N. Martin, Charles R. Hulten, and David Campbell (1992). "Productivity Dynamics in Manufacturing Plants." Brookings Papers on Economic Activity: Microeconomics, 1992, 187-249.

Balasubramanian, Natarajan and Jagadeesh Sivadasan (2011). "What Happens When Firms Patent? New Evidence from U.S. Economic Census Data." Review of Economics and Statistics, 93, 126-146.

Bernard, Andrew B. and J. Bradford Jensen (1999). "Exceptional Exporter Performance: Cause, Effect, or Both?" Journal of International Economics, 47, 1-25.

Bernard, Andrew B., J. Bradford Jensen, and Peter Schott (2006). "Transfer Pricing by U.S.-Based Multinational Firms." NBER Working Paper No. 12493.

Bloom, Nicholas and John Van Reenen (2010). "Why Do Management Practices Differ Across Firms and Countries?" Journal of Economic Perspectives, 24, 203-224.

Blundell, Richard and Stephen Bond (2000). "GMM Estimation with Persistent Panel Data: An Application to Production Functions." Econometric Reviews, 19, 321-340.

Caves Douglas, Laurits Christensen, and Erwin Diewert (1982). "Multilateral Comparisons of Output, Input, and Productivity Using Superlative Index Numbers." Economic 
Journal, 92, 73-86.

Collard-Wexler, Allan and Jan De Loecker (2013). "Reallocation and Technology: Evidence from the U.S. Steel Industry." NBER Working Paper No. 18739.

Davis, Steven, Cheryl Grim, and John Haltiwanger (2008). "Productivity Dispersion and Input Prices: The Case of Electricity." CES Working Paper Series No. 08-33.

Dubé, Jean-Pierre, Günter J. Hitsch, and Peter E. Rossi (2010). "State Dependence and Alternative Explanations for Consumer Inertia." RAND Journal of Economics, 41, 417445.

Eslava, Marcela, John Haltiwanger, Adriana Kugler, and Maurice Kugler (2004). "The Effects of Structural Reforms on Productivity and Profitability Enhancing Reallocation: Evidence from Colombia." Journal of Development Economics, 75, 333-371.

Eslava, Marcela, John Haltiwanger, Adriana Kugler, and Maurice Kugler (2013). "Trade Reforms and Market Selection: Evidence from Manufacturing Plants in Colombia." Review of Economic Dynamics, 16, 135-158.

Foster, Lucia, John Haltiwanger, and C. J. Krizan (2001). "Aggregate Productivity Growth: Lessons from Microeconomic Evidence." In New Developments in Productivity Analysis, edited by Charles R. Hulten, Edwin R. Dean, and Michael J. Harper. Chicago: University of Chicago Press, 303-372.

Foster, Lucia, John Haltiwanger, and Chad Syverson (2008). "Reallocation, Firm Turnover, and Efficiency: Selection on Productivity or Profitability?" American Economic Review, $98,394-425$.

Fox, Jeremy and Valérie Smeets (2011). "Does Input Quality Drive Measured Differences in Firm Productivity?" International Economic Review, 52, 961-989.

Gandhi, Amit, Salvador Navarro, and David Rivers (2012). "On the Identification of Production Functions: How Heterogeneous is Productivity?" Working paper, University of Wisconsin, Madison.

Gorodnichenko, Yuriy (2010). "Using Firm Optimization to Evaluate and Estimate Productivity and Returns to Scale." Working paper, University of California, Berkeley.

Griliches, Zvi and Haim Regev (1995). "Firm Productivity in Israeli Industry: 1979-1988." Journal of Econometrics, 65, 175-203.

Hsieh, Chang-Tai and Peter J. Klenow (2009). "Misallocation and Manufacturing TFP in China and India." Quarterly Journal of Economics, 124, 1403-1448.

Katayama, Hajime, Shihua Lu, and James R. Tybout (2009). "Firm-Level Productivity Studies: Illusions and a Solution." International Journal of Industrial Organization, 27, 403-413.

Kellogg, Ryan (2011). "Learning by Drilling: Inter-Firm Learning and Relationship Persis- 
tence in the Texas Oilpatch." Quarterly Journal of Economics, 126, 1961-2004.

Klump, Rainer, Peter McAdam, and Alpo William (2012). "The Normalized CES Production Function: Theory and Empirics." Journal of Economic Surveys, 26, 769-799.

Kugler, Maurice and Eric Verhoogen (2012). "Prices, Plant Size, and Product Quality." Review of Economic Studies, 79, 307-339.

Manova, Kalina and Zhiwei Zhang (2012). "Export Prices Across Firms and Destinations." Quarterly Journal of Economics, 127, 379-436.

Olley, G. Steven and Ariel Pakes (1996). "The Dynamics of Productivity in the Telecommunications Equipment Industry." Econometrica, 64, 1263-1297.

Ornaghi, Carmine (2006). "Assessing the Effects of Measurement Errors on the Estimation of Production Functions." Journal of Applied Econometrics, 21, 879-891.

Raval, Devesh (2011). "Non Neutral Technology and the Microeconomic Production Function." CES Working Paper Series No. 11-05.

Roberts, Mark J. and Dylan Supina (1996). "Output Price, Markups, and Producer Size." European Economic Review, 40, 909-921.

Roberts, Mark J. and Dylan Supina (2000). "Output Price and Markup Dispersion in Micro Data: The Roles of Producer Heterogeneity and Noise." In Advances in Applied Microeconomics, Vol. 9, Industrial Organization, edited by Michael R. Baye. Greenwich: JAI Press, 1-36.

Syverson, Chad (2004a). "Product Substitutability and Productivity Dispersion." Review of Economics and Statistics, 86, 534-550.

Syverson, Chad (2004b). "Market Structure and Productivity: A Concrete Example." Journal of Political Economy, 112, 1181-1222.

U.S. Department of the Interior (1989). Cement Mineral Yearbook.

U.S. Department of Transportation, Bureau of Transportation Statistics (2009). Table 3-21: Average Freight Revenue Per Ton-mile.

van Biesebroeck, Johannes (2008). "The Sensitivity of Productivity Estimates: Revisiting Three Important Debates." Journal of Business and Economic Statistics, 26, 311-328. 


\section{A.3 Substitution Between Material Inputs and Other Inputs}

The empirical analysis of Section 3 invokes the assumption that the elasticity of substitution, $\hat{\varrho}$, between material inputs and all other inputs equals 1 (see Assumption 1). In reality, material inputs are likely to be complements to other inputs. In this subsection, I analyze how the dispersion of $\phi$ differs under different assumptions on $\hat{\varrho}$.

Consider a plant with technical efficiency $\Phi_{i j t}$. Assume that, for plant $i$, the price of a unit of the "priced" intermediate input is $P_{i j t}^{i n}$, and let the corresponding industry-year average be $\bar{P}_{j t}^{i n}$. The prices of the other inputs are assumed to be the same for all plants in the industry-year (see Assumption 2). With an elasticity of substitution of $\hat{\varrho}$, plant $i$ 's marginal cost equals:

$$
M C_{i j t}=\frac{1}{\Phi_{i j t}}\left[S_{j t} \cdot \sigma_{j t} \cdot\left(\frac{P_{i j t}^{i n}}{\bar{P}_{j t}^{i n}}\right)^{1-\hat{\varrho}}+1-S_{j t} \cdot \sigma_{j t}\right]^{\frac{1}{1-\hat{\varrho}}}
$$

As in Section $3, \sigma_{j t} \cdot S_{j t}$ refers to the expenditure share of "priced" materials. Equation 25 states that plants' marginal costs are determined by their technical efficiencies $\left(\Phi_{i j t}\right)$ and the composite price that they face for intermediate inputs and other inputs. The elasticity, $\hat{\varrho}$, dictates how the prices of intermediate inputs and other inputs are combined. As $\varrho$ decreases, a larger weight is allotted to the input with a higher relative price.

Re-arranging Equation 25 yields the following expression for $\Phi_{i j t}$ in terms of $T F P Q_{i j t}$ and $P_{i j t}^{i n}$ :

$$
\Phi_{i j t}=T F P Q_{i j t}\left[S_{j t} \cdot \sigma_{j t} \cdot\left(\frac{P_{i j t}^{i n}}{\bar{P}_{j t}^{i n}}\right)^{1-\hat{\varrho}}+1-S_{j t} \cdot \sigma_{j t}\right]^{\frac{1}{1-\hat{\varrho}}}
$$

For the pooled benchmark sample, I use Equation 26 to compute the standard deviation of $\phi_{i j t}$, for $\hat{\varrho} \in\{0.2,0.4, .0 .6,0.8,1.0\}$. These results, which are presented in Table 19, illustrate that the dispersion of $\phi$ is robust to changes in the elasticity of substitution, even as $\hat{\varrho}$ approaches 0 . Varying the elasticity of substitution, $\hat{\varrho}$, only has a noticeable effect on the measured technical efficiency for plants that have very small or very large values of $P_{i j t}^{i n} \div \bar{P}_{j t}^{i n}$. Since most plants have materials prices that are close to the industry average, $\hat{\varrho}$ does not substantially alter the measured dispersion of $\phi$.

\section{A.4 Substitution Across Material Inputs}

Throughout the body of the paper, I assume that the elasticity of substitution between different material inputs - for industries that use multiple material inputs - is 0 (see As- 


\begin{tabular}{ccccccc}
\hline & $\hat{\varrho}$ & 0.2 & 0.4 & 0.6 & 0.8 & 1.0 \\
\hline Revenue- & Yes & 0.1507 & 0.1507 & 0.1507 & 0.1507 & 0.1506 \\
weighted? & No & 0.2193 & 0.2192 & 0.2192 & 0.2191 & 0.2191 \\
\hline
\end{tabular}

Table 19: Dispersion of $\phi$, as computed using Equations 9 and 26.

Notes: The dispersion of $\phi$, when $\varrho \varrho=1.0$, equals the value given in the final row of Table $3 . \mathrm{N}=10,503$.

\begin{tabular}{lcccccccc}
\hline Sample & $\begin{array}{l}\text { Revenue- } \\
\text { weighted? }\end{array}$ & $90 / 10$ & $\mathrm{SD}$ & $90 / 10$ & $\mathrm{SD}$ & $90 / 10$ & $\mathrm{SD}$ & $N$ \\
\hline$\varrho$ & & 0.1 & 0.1 & 0.3 & 0.3 & 0.5 & 0.5 & \\
\hline Concrete & No & 0.5223 & 0.2302 & 0.5223 & 0.2302 & 0.5222 & 0.2303 & 3708 \\
& Yes & 0.4864 & 0.2151 & 0.4863 & 0.2151 & 0.4862 & 0.2151 & 3708 \\
Pooled & No & 0.4930 & 0.2190 & 0.4929 & 0.2190 & 0.4928 & 0.2191 & 10,503 \\
& Yes & 0.3240 & 0.1506 & 0.3240 & 0.1506 & 0.3240 & 0.1506 & 10,503 \\
\hline
\end{tabular}

Table 20: Dispersion of $\phi$, as computed using Equations 8, 9, and 27.

sumption 4). For plants that produce ready-mix concrete, I assess the importance of the assumption that plants may not substitute across different material inputs.

When the elasticity of substitution between gravel/sand and cement is constant (but not necessarily 0 ), the price of a bundle of material inputs equals:

$$
P_{i j t}^{i n} \equiv\left[\frac{s_{j t}^{\text {Gravel }}}{s_{j t}^{\text {Gravel }}+s_{j t}^{\text {Cement }}} \cdot\left(\frac{P_{\text {Gravel }, i j t}^{i n}}{\bar{P}_{\text {Gravel }, j t}^{i n}}\right)^{1-\varrho}+\frac{s_{j t}^{\text {Cement }}}{s_{j t}^{\text {Gravel }}+s_{j t}^{\text {Cement }}} \cdot\left(\frac{P_{\text {Cement }, i j t}^{\text {in }}}{\bar{P}_{\text {Cement }, j t}^{i n}}\right)^{1-\varrho}\right]^{\frac{1}{1-\varrho}}
$$

In Equation 27, $s_{j t}^{\text {Gravel }}$ refers to the share of materials expenditures that go to gravel, $P_{\text {Gravel, } i j t}^{i n}$ is the price that plant $i$ pays per 1000 pounds of gravel in year $t, \bar{P}_{\text {Gravel, } i j t}^{i n}$ is the geometric average of the price paid by all ready-mix concrete producing plants in year $t$, and $\varrho$ is the elasticity of substitution between cement and sand/gravel. In the baseline analysis, I had set $\varrho=0$.

Using Equation 27, I compute ready-mix concrete plants' materials prices. I then recompute $\Phi_{i j t}$, using Equation 8, and $\phi_{i j t}$, using Equation 9. The dispersion of $\phi$ is given in Table 20. As $\varrho$ increases, the price of a bundle of intermediate inputs decreases for plants that have exceptionally cheap input prices for one of the two intermediate inputs. Also, as $\varrho$ increases, the relative price of the bundle increases for plants that pay roughly the same relative price for the two intermediate inputs. It turns out that, in combination, these two effects have almost no impact on the overall dispersion of $\phi$. 


\section{A.5 An Alternative Measure of Plant Productivity}

In this subsection, I re-compute Tables 2 and 3, using the productivity measure discussed in Caves, Christensen, and Diewert (1982) (hereafter, CCD). Unlike the current paper, which uses a Cobb-Douglas productivity measure, CCD assume that plants' production technologies take the (more flexible) translog form. Moreover, the parameters of this production function are allowed to vary across the plants within an industry. A third difference, between the current paper and CCD, is that the latter paper invokes the assumption that plants (flexibly) choose inputs to minimize costs.

The set-up in Caves, Christensen, and Diewert (1982) yields the following comparison of plants' productivities (see Equation 33 of that paper): ${ }^{49}$

$$
\Phi_{i j t}^{C C D} \equiv Q_{i j t} \cdot\left(L_{i j t}\right)^{-\frac{\lambda_{j t}+\lambda_{i j t}}{2}} \cdot\left(K_{i j t}\right)^{-\frac{\kappa_{j t}+\kappa_{i j t}}{2}} \cdot\left(E_{i j t}\right)^{-\frac{\epsilon_{j t}+\epsilon_{i j t}}{2}} \cdot\left(N_{i j t}\right)^{-\frac{\sigma_{j t}+\sigma_{i j t}}{2}} .
$$

In Equation 28, $\lambda_{j t}, \kappa_{j t}, \epsilon_{j t}$, and $\sigma_{j t}$ are the industry average cost shares of labor, capital, electricity, and materials (as in Section 2.4), while $\lambda_{i j t}, \kappa_{i j t}, \epsilon_{i j t}$, and $\sigma_{i j t}$ are the corresponding plant-specific cost shares. The other two productivity measures are defined as follows:

$$
\begin{aligned}
& \text { TFPQ } Q_{i j t}^{C C D}=\Phi_{i j t} \cdot\left(P_{i j t}^{i n}\right)^{-\frac{\sigma_{j t}+\sigma_{i j t}}{2}} \\
& T F P R_{i j t}^{C C D}=T F P Q_{i j t}^{C C D} \cdot P_{i j t}^{o u t}
\end{aligned}
$$

Table 21 recomputes the within-industry productivity dispersions, using the CCD approach for computing plants' productivities. Here, too, the main results of Table 3 survive. The difference in the dispersion of $t f p q$ and $\phi$ ranges between $4.5 \%$ and $12.8 \%$, and is statistically different from 0 for five of the six measures. Thus, the different methodology-due to CCD - yields very similar conclusions regarding the dispersion of measured productivity that is attributable to materials price variation.

\section{A.6 More Correlations}

Table 22 presents correlations among plant-level characteristics for each of the 10 industries in the benchmark sample.

\footnotetext{
${ }^{49}$ Unfortunately, I can't apply the CCD methodology exactly. In that paper, the authors assume that each plant produces every relevant output and uses every relevant input. To give an example, when comparing plants in the ready-mix concrete industry, if there are some plants that manufacture concrete bricks (a product distinct from ready-mix concrete), then all plants must produce at least some concrete bricks. This assumption turns out to be violated in the data. For this reason, I deflate input purchases in the manner described by Equation 1.
} 


\begin{tabular}{cccccccccc}
\hline Revenue- & \multicolumn{2}{c}{ Dispersion of $t f p q^{C C D}$} & \multicolumn{3}{c}{ Dispersion of $\phi^{C C D}$} & \multicolumn{3}{c}{ Percent Decline } \\
weighted? & $90 / 10$ & $75 / 25$ & SD & $90 / 10$ & $75 / 25$ & SD & $90 / 10$ & $75 / 25$ & SD \\
\hline Yes & 0.438 & 0.203 & 0.193 & 0.391 & 0.193 & 0.177 & $12.8 \%^{*}$ & $5.7 \%$ & $6.4 \%^{*}$ \\
No & 0.521 & 0.249 & 0.234 & 0.489 & 0.234 & 0.219 & $6.7 \%^{*}$ & $6.5 \%^{*}$ & $4.5 \%^{*}$ \\
\hline
\end{tabular}

Table 21: Dispersion of $t f p q$ and $\phi$.

Notes: In the final three columns, stars indicate that the difference between $t f p q$ and $\phi$ is statistically significant, at the $5 \%$ level (see Web Appendix C for details).

\begin{tabular}{lccccccc}
\hline \multicolumn{1}{c}{ Sample } & $p^{\text {in }}, t f p q$ & $p^{\text {in }}, \phi$ & $p^{\text {in }}, p^{\text {out }}$ & $p^{\text {in }}, t f p r$ & $\phi, t f p q$ & $t f p q$, tfpr & $t f p q, p^{\text {out }}$ \\
\hline Boxes, Yr. $\leq 87$ & $-0.286^{*}$ & $0.226^{*}$ & $0.280^{*}$ & -0.042 & $0.868^{*}$ & $0.418^{*}$ & $-0.797^{*}$ \\
Boxes, Yr. ${ }^{\prime} 92$ & $-0.352^{*}$ & 0.089 & $0.286^{*}$ & $-0.086^{*}$ & $0.901^{*}$ & $0.116^{*}$ & $-0.877^{*}$ \\
Coffee & $-0.485^{*}$ & 0.030 & $0.343^{*}$ & -0.227 & $0.855^{*}$ & $0.592^{*}$ & $-0.584^{*}$ \\
Concrete & $-0.306^{*}$ & $0.120^{*}$ & $0.276^{*}$ & $-0.127^{*}$ & $0.908^{*}$ & $0.740^{*}$ & $-0.476^{*}$ \\
Flour & $-0.394^{*}$ & $0.468^{*}$ & $0.312^{*}$ & -0.011 & $0.628^{*}$ & 0.128 & $-0.722^{*}$ \\
Gasoline & $-0.395^{*}$ & $0.141^{*}$ & $0.171^{*}$ & $-0.310^{*}$ & $0.854^{*}$ & $0.824^{*}$ & $-0.368^{*}$ \\
Milk, Bulk & $-0.424^{*}$ & -0.149 & $0.410^{*}$ & -0.072 & $0.958^{*}$ & $0.444^{*}$ & $-0.770^{*}$ \\
Milk, Packaged & $-0.281^{*}$ & 0.049 & $0.225^{*}$ & $-0.104^{*}$ & $0.945^{*}$ & $0.435^{*}$ & $-0.754^{*}$ \\
Sugar & -0.034 & $0.481^{*}$ & $0.237^{*}$ & 0.100 & $0.860^{*}$ & $0.858^{*}$ & $-0.466^{*}$ \\
Yarn & $-0.301^{*}$ & 0.197 & $0.211^{*}$ & $-0.174^{*}$ & $0.875^{*}$ & $0.491^{*}$ & $-0.763^{*}$ \\
Pooled & $-0.369^{*}$ & $0.127^{*}$ & $0.231^{*}$ & $-0.232^{*}$ & $0.873^{*}$ & $0.694^{*}$ & $-0.551^{*}$ \\
\hline
\end{tabular}

Table 22: Correlations among plant-level characteristics.

Notes: Stars indicate that the correlation is significantly different from 0 , at the $5 \%$ level (see Web Appendix C for details).

For several of the correlations, the subsample of raw cane sugar manufacturing plants is anomalous. For this industry, plants' marginal costs are unrelated to their materials prices. Moreover, the correlation between input prices and technical efficiencies is much stronger (48\%) than for other subsamples. These patterns are somewhat puzzling. Most likely, either there is substantial measurement error in the physical units that cane sugar refiners use, or there is significant quality heterogeneity among the raw cane sugar manufacturers.

Except for the raw cane sugar industry, correlations among plant-level characteristics are qualitatively similar across the different industries in the benchmark sample. The correlation between materials prices and quantity productivities is moderately negative for the nine other industries, while the correlation between quantity productivities and output prices is strongly negative (ranging between $-37 \%$ and $-88 \%$ ). Finally, the three productivity measures are always highly correlated with one another, with the correlation between $\phi$ and $t f p q$ being larger than the correlation between $t f p q$ and $t f p r$. 


\section{A.7 Measurement Error}

As discussed in Section 3.2, measurement error in the quantities that a plant consumes or produces has the potential to bias the correlations among plant-level characteristics. In this subsection, I assess the importance of measurement error.

To do so, I perform an exercise in which I add a randomly-generated disturbance to plant-level input and output quantities, and then re-compute the plant-level productivity measures. In particular, for each of the 10,503 plant-year observations in the benchmark sample, I take two draws from a standard normal distribution. Use $v_{i j t}$ and $\varpi_{i j t}$ to refer to these randomly-generated numbers for plant $i$, in industry $j$, and year $t$. I apply these randomly-generated numbers to the physical quantities of input and output purchases, yielding "contaminated" physical quantity measures:

$$
\begin{aligned}
& \hat{q}_{i j t}=q_{i j t}+\vartheta \cdot v_{i j t} \\
& \hat{n}_{i j t}=n_{i j t}+\vartheta \cdot \varpi_{i j t}
\end{aligned}
$$

In Equation 29-30, and throughout the rest of this subsection, $\hat{x}$ will refer to the version of any plant-level characteristic, $x$, that is imbued with extra measurement error. $\vartheta$ is a parameter that characterizes the amount extra measurement error.

The definitions of plants' input prices, output prices, and productivity measures follow from Equations 29-30, in combination with Equations 3-8:

$$
\begin{aligned}
\hat{p}_{i j t}^{o u t} & =p_{i j t}^{o u t}-\vartheta \cdot v_{i j t} \\
\hat{p}_{i j t}^{i n} & =p_{i j t}^{i n}-\vartheta \cdot \varpi_{i j t} \\
\widehat{t f p q_{i j t}} & =t f p q_{i j t}+\vartheta \cdot v_{i j t} \\
\hat{\phi}_{i j t} & =\phi_{i j t}+\vartheta \cdot v_{i j t}-S_{j t} \cdot \sigma_{j t} \cdot \vartheta \cdot \varpi_{i j t}
\end{aligned}
$$

In this exercise, no extra measurement error is applied to the revenue productivity measure (tfpr), because both $q_{i j t}$ and $n_{i j t}$ are absent in the computation of this variable.

Correlations among the contaminated plant-level characteristics are presented in Table

23. Table 24 displays the standard deviations of $\hat{\phi}, \widehat{t f p q}, \widehat{p^{\text {in }}}$, and $\widehat{p^{\text {out }}}$, in addition to the 5 -year autocorrelation coefficients of $\hat{\phi}, \widehat{t f p q}, \widehat{p^{\text {in }}}$, and $\widehat{p^{\text {out }}}$. The takeaways from Tables 23 and 24 are that measurement error in input and output quantities magnifies the correlation between input prices and technical efficiency, and between output prices and quantity productivity. Second, measurement error attenuates the correlation between input prices and quantity productivity, and between input prices and revenue productivity. Third, measurement error increases the dispersions of quantity productivity and technical efficiency, 


\begin{tabular}{cccccccc}
\hline$\vartheta$ & $\widehat{p^{\text {in }}}, \widehat{t f p q}$ & $\widehat{p^{\text {in }}, \widehat{\phi}}$ & $\widehat{p^{\text {in }}, \widehat{p^{\text {out }}}}$ & $\widehat{p^{\text {in }}}, t f p r$ & $\widehat{\phi}, \widehat{t f p q}$ & $\widehat{t f p q}, t f p r$ & $\widehat{t f p q}, \widehat{p^{\text {out }}}$ \\
\hline 0.01 & -0.366 & 0.128 & 0.226 & -0.234 & 0.874 & 0.694 & -0.553 \\
0.02 & -0.360 & 0.135 & 0.218 & -0.234 & 0.874 & 0.691 & -0.558 \\
0.03 & -0.350 & 0.147 & 0.207 & -0.232 & 0.873 & 0.687 & -0.568 \\
0.04 & -0.337 & 0.163 & 0.195 & -0.229 & 0.872 & 0.680 & -0.580 \\
0.05 & -0.323 & 0.182 & 0.182 & -0.225 & 0.870 & 0.671 & -0.595 \\
0.06 & -0.306 & 0.203 & 0.168 & -0.220 & 0.868 & 0.660 & -0.612 \\
0.07 & -0.289 & 0.226 & 0.155 & -0.215 & 0.865 & 0.648 & -0.631 \\
0.08 & -0.271 & 0.249 & 0.141 & -0.208 & 0.863 & 0.635 & -0.650 \\
0.09 & -0.254 & 0.272 & 0.128 & -0.202 & 0.860 & 0.621 & -0.669 \\
0.10 & -0.237 & 0.294 & 0.116 & -0.195 & 0.857 & 0.607 & -0.688 \\
\hline
\end{tabular}

Table 23: Biases generated by measurement error.

Notes: The table presents correlations among plant-level characteristics. In a given row, the standard deviation of the extra measurement error is given by $\vartheta$. In the calculations, observations are weighed by real revenues.

with a larger increase in the dispersion of the technical efficiency term. (Since the technical efficiency term is computed using both input and output quantities, it is the more sensitive to measurement error.) Finally, measurement error reduces the estimated persistence of the plant-level input prices, output prices, and productivity measures.

\section{A.8 Unweighted Results}

In this subsection, I present the unweighted versions of Tables 2, 3, 6, 14, 15, and 22. In the benchmark calculations, observations are revenue weighted. To preview the main results, all of the main conclusions of Section 3 are robust to the weighting scheme.

The first two tables, Tables 25 and 26, give the correlations among plant-level statistics. Overall, the correlation between $p^{\text {in }}$ and $p^{\text {out }}$ is somewhat larger, while the correlation between $p^{i n}$ and $t f p q$ is somewhat closer to 0 , compared to the correlations contained in Tables 2 and 22 .

Compared to the revenue-weighted calculations, the unweighted dispersions of $t f p r$, $t f p q$, and $\phi$ are larger (see the first eleven rows of Table 27 for the benchmark sample, and the final five rows for the Quality Variation sample). The larger dispersions have two sources. First, revenue weighting gives more importance to high revenue-per-plant industries. Since gasoline, which by far has the largest average revenues among the industries in the benchmark sample, has more compressed $t f p r$, $t f p q$, and $\phi$ distributions, assigning weights by revenue causes the pooled dispersion to be larger in the unweighted calculations. Second, the unweighted calculations give relatively more weight, within industries, to the low productivity, low employment plants, again causing unweighted dispersions to be larger 


\begin{tabular}{ccccc|cccc}
\hline \multicolumn{6}{c|}{ Std. Dev. } & \multicolumn{4}{c}{ Persistence } \\
\hline$\vartheta$ & $\widehat{t f p q}$ & $\widehat{\phi}$ & $\widehat{p^{\text {out }}}$ & $\widehat{p^{\text {in }}}$ & $\widehat{t f p q}$ & $\widehat{\phi}$ & $p^{\text {in }}$ & $\widehat{p^{\text {out }}}$ \\
\hline 0.01 & 0.161 & 0.151 & 0.117 & 0.119 & 0.180 & 0.186 & 0.320 & 0.305 \\
0.02 & 0.162 & 0.152 & 0.117 & 0.120 & 0.184 & 0.185 & 0.308 & 0.300 \\
0.03 & 0.163 & 0.155 & 0.119 & 0.121 & 0.187 & 0.182 & 0.290 & 0.292 \\
0.04 & 0.165 & 0.158 & 0.121 & 0.124 & 0.189 & 0.177 & 0.268 & 0.281 \\
0.05 & 0.168 & 0.162 & 0.124 & 0.127 & 0.189 & 0.170 & 0.244 & 0.268 \\
0.06 & 0.171 & 0.166 & 0.128 & 0.131 & 0.189 & 0.163 & 0.217 & 0.254 \\
0.07 & 0.174 & 0.172 & 0.132 & 0.135 & 0.187 & 0.154 & 0.191 & 0.239 \\
0.08 & 0.178 & 0.177 & 0.136 & 0.140 & 0.185 & 0.146 & 0.165 & 0.224 \\
0.09 & 0.182 & 0.184 & 0.142 & 0.145 & 0.182 & 0.137 & 0.141 & 0.210 \\
0.10 & 0.187 & 0.191 & 0.147 & 0.151 & 0.178 & 0.128 & 0.118 & 0.197 \\
\hline
\end{tabular}

Table 24: Biases generated by measurement error.

Notes: The first four columns give the standard deviations of quantity productivity, technical efficiency, input prices, and output prices, while the final four columns present the 5-year autocorrelation coefficients of the same variables. In a given row, the standard deviation of the extra measurement error is given by $\vartheta$. In the calculations, observations are weighed by real revenues.

\begin{tabular}{lccccc}
\hline & $p^{\text {in }}$ & $p^{\text {out }}$ & $t f p q$ & $\phi$ & $t f p r$ \\
\hline$p^{\text {out }}$ & $0.278^{*}$ & & & & \\
$t f p q$ & $-0.303^{*}$ & $-0.653^{*}$ & & & \\
$\phi$ & $0.141^{*}$ & $-0.549^{*}$ & $0.899^{*}$ & & \\
$t f p r$ & $-0.098^{*}$ & $0.212^{*}$ & $0.601^{*}$ & $0.581^{*}$ & \\
Std. Dev. & 0.167 & 0.186 & 0.227 & 0.219 & 0.176 \\
\hline
\end{tabular}

Table 25: Correlations and standard deviations of plant-level characteristics.

Notes: Correlations give equal weight to all plant-year observations. Stars indicate that the correlation is significantly different from 0 , at the $5 \%$ level (see Web Appendix C for details). Also, see Table 2 for the real-revenue-weighted version of this table. $\mathrm{N}=10,503$. 


\begin{tabular}{lccccccc}
\hline \multicolumn{1}{c}{ Sample } & $p^{\text {in }}, t f p q$ & $p^{\text {in }}, \phi$ & $p^{\text {in }}, p^{\text {out }}$ & $p^{\text {in }}$, tfpr & $\phi, t f p q$ & tfpq, tfpr & tfpq, $p^{\text {out }}$ \\
\hline Boxes, Yr. $\leq 87$ & $-0.406^{*}$ & $0.153^{*}$ & $0.404^{*}$ & $-0.061^{*}$ & $0.841^{*}$ & $0.425^{*}$ & $-0.824^{*}$ \\
Boxes, Yr. ${ }^{*} 92$ & $-0.428^{*}$ & $0.142^{*}$ & $0.366^{*}$ & -0.070 & $0.834^{*}$ & $0.127^{*}$ & $-0.873^{*}$ \\
Coffee & $-0.293^{*}$ & $0.227^{*}$ & $0.300^{*}$ & -0.027 & $0.862^{*}$ & $0.517^{*}$ & $-0.645^{*}$ \\
Concrete & $-0.271^{*}$ & $0.107^{*}$ & $0.234^{*}$ & $-0.132^{*}$ & $0.928^{*}$ & $0.776^{*}$ & $-0.458^{*}$ \\
Flour & $-0.344^{*}$ & $0.454^{*}$ & $0.256^{*}$ & -0.073 & $0.681^{*}$ & $0.254^{*}$ & $-0.715^{*}$ \\
Gasoline & $-0.353^{*}$ & $0.203^{*}$ & $0.125^{*}$ & $-0.305^{*}$ & $0.844^{*}$ & $0.840^{*}$ & $-0.396^{*}$ \\
Milk, Bulk & $-0.280^{*}$ & 0.033 & $0.382^{*}$ & 0.079 & $0.950^{*}$ & $0.522^{*}$ & $-0.789^{*}$ \\
Milk, Packaged & $-0.282^{*}$ & $0.054^{*}$ & $0.237^{*}$ & $-0.095^{*}$ & $0.943^{*}$ & $0.456^{*}$ & $-0.753^{*}$ \\
Sugar & 0.055 & $0.459^{*}$ & 0.116 & 0.118 & $0.912^{*}$ & $0.889^{*}$ & $-0.405^{*}$ \\
Yarn & $-0.354^{*}$ & 0.117 & $0.297^{*}$ & $-0.135^{*}$ & $0.887^{*}$ & $0.455^{*}$ & $-0.788^{*}$ \\
Pooled-Benchmark & $-0.303^{*}$ & $0.141^{*}$ & $0.278^{*}$ & $-0.098^{*}$ & $0.899^{*}$ & $0.601^{*}$ & $-0.653^{*}$ \\
\hline
\end{tabular}

Table 26: Correlations among plant-level characteristics.

Notes: Correlations give equal weight to all plant-year observations. Stars indicate that the correlation is significantly different from 0 , at the $5 \%$ level (see Web Appendix C for details). See Table 22 for the real-revenue-weighted version of this table.

than the weighted dispersions.

For the pooled benchmark sample, the decline in dispersion is smaller when observations given equal weight. For example, compared to the $8.8 \%$ decline that is given in Table 3 , the $90 / 10$ ratio of $t f p q$ is only $7.2 \%$ larger than the $90 / 10$ ratio of $\phi$. The difference, between the unweighted and weighted calculations, is due to differences in the weight that particular industries get. When observations are given equal weight, the ready-mix concrete industry (which had a particularly small decline in productivity dispersion) is relatively more important in the calculations. On the other hand, when observations are revenue weighted, the gasoline industry (which has a slightly larger than average decline in productivity dispersion) is relatively more important in the calculations. Note that, weighing observations by revenue does not cause the within-industry declines in dispersion to be systematically larger or smaller. For the sample of industries with substantial variation in output quality, there are no systematic differences between the weighted and unweighted calculations (compare Table 14 and the final five rows of Table 27).

Finally, Table 28 presents the unweighted versions of Tables 6 and 15 .

\section{A.9 An Alternative Growth Decomposition}

In this subsection, I reproduce the analysis of Section 3.5, using the decomposition method of Griliches and Regev (1995). Relative to the Foster, Haltiwanger, and Krizan (2001) decomposition, the Griliches and Regev (1995) decomposition replaces $\overline{t f p}_{t-1}$ with $\frac{1}{2} \overline{t f p}_{t-1}+\frac{1}{2} \overline{t f p}_{t}$ in the "Entry Effect" and "Exit Effect" terms: 


\begin{tabular}{|c|c|c|c|c|c|c|c|c|c|}
\hline & \multicolumn{3}{|c|}{ Dispersion of $t f p q$} & \multicolumn{3}{|c|}{ Dispersion of $\phi$} & \multicolumn{3}{|c|}{ Percent Decline } \\
\hline Sample & $90 / 10$ & $75 / 25$ & SD & $90 / 10$ & $75 / 25$ & SD & $90 / 10$ & $75 / 25$ & SD \\
\hline Boxes, Year $\leq 87$ & 0.475 & 0.204 & 0.199 & 0.409 & 0.196 & 0.185 & $17.3 \% *$ & $4.1 \% *$ & $8.1 \% *$ \\
\hline Boxes, Year $\geq ' 92$ & 0.617 & 0.318 & 0.242 & 0.548 & 0.278 & 0.221 & $13.4 \% *$ & $15.7 \%^{*}$ & $10.1 \% *$ \\
\hline Coffee & 0.635 & 0.321 & 0.257 & 0.569 & 0.272 & 0.249 & $12.3 \% *$ & $19.6 \% *$ & $3.3 \%$ \\
\hline Concrete & 0.558 & 0.275 & 0.238 & 0.522 & 0.260 & 0.230 & $7.1 \% *$ & $5.8 \% *$ & $3.4 \% *$ \\
\hline Flour & 0.404 & 0.205 & 0.163 & 0.396 & 0.176 & 0.172 & $2.0 \%$ & $17.9 \%^{*}$ & $-5.3 \%$ \\
\hline Gasoline & 0.309 & 0.151 & 0.147 & 0.296 & 0.137 & 0.141 & $4.6 \%$ & $10.7 \%$ & $4.8 \%$ \\
\hline Milk, Bulk & 0.809 & 0.306 & 0.316 & 0.681 & 0.322 & 0.303 & $20.6 \% *$ & $-4.8 \%$ & $4.4 \%$ \\
\hline Milk, Packaged & 0.564 & 0.284 & 0.235 & 0.531 & 0.262 & 0.226 & $6.5 \% *$ & $8.9 \% *$ & $4.2 \% *$ \\
\hline Sugar & 0.692 & 0.330 & 0.313 & 0.807 & 0.352 & 0.352 & $-13.2 \% *$ & $-6.3 \%$ & $-10.6 \% *$ \\
\hline Yarn & 0.620 & 0.310 & 0.262 & 0.629 & 0.312 & 0.248 & $-1.4 \%$ & $-0.6 \%$ & $5.6 \% *$ \\
\hline Pooled-Benchmark & 0.527 & 0.253 & 0.227 & 0.493 & 0.238 & 0.219 & $7.2 \% *$ & $6.5 \% *$ & $3.9 \% *$ \\
\hline Pickles & 0.890 & 0.441 & 0.346 & 0.962 & 0.471 & 0.368 & $-7.3 \%$ & $-6.2 \%$ & $-5.8 \%$ \\
\hline Sausages & 0.800 & 0.409 & 0.316 & 0.730 & 0.358 & 0.308 & $10.0 \% *$ & $15.3 \%^{*}$ & $2.5 \%$ \\
\hline Softwood & 1.379 & 0.675 & 0.490 & 1.310 & 0.651 & 0.489 & $5.4 \%$ & $3.6 \%$ & $0.2 \%$ \\
\hline Wi & 1.407 & 0.735 & 0.502 & 1.444 & 0.779 & 0.536 & $-2.6 \%$ & $-5.4 \%$ & $-6.1 \%$ \\
\hline Pooled-Quality & 1.028 & 0.500 & 0.400 & 1.021 & 0.477 & 0.410 & $0.7 \%$ & $4.8 \%$ & $-2.5 \%$ \\
\hline
\end{tabular}

Table 27: Dispersion of $t f p q$ and $\phi$.

Notes: All observations are given equal weight. In the final three columns, stars indicate that he difference between $t f p q$ and $\phi$ is statistically significant, at the $5 \%$ level (see Web Appendix C for details).

\begin{tabular}{lccc}
\hline \multicolumn{1}{c}{ Sample } & $\beta$ & s.e. & Adjusted $R^{2}$ \\
\hline Boxes, Yr. $\leq$ ' 87 & 0.693 & 0.116 & 0.019 \\
Boxes, Yr. $\geq 92$ & 0.538 & 0.182 & 0.012 \\
Coffee & -0.137 & 0.092 & 0.004 \\
Concrete & 0.854 & 0.030 & 0.184 \\
Flour & 0.254 & 0.093 & 0.013 \\
Gasoline & 0.618 & 0.058 & 0.138 \\
Milk, Bulk & 0.322 & 0.152 & 0.027 \\
Milk, Packaged & 0.821 & 0.041 & 0.160 \\
Sugar & 0.081 & 0.191 & -0.005 \\
Yarn & 0.024 & 0.339 & -0.002 \\
Pooled-Benchmark & 0.606 & 0.021 & 0.072 \\
\hline Pickles & -0.038 & 0.196 & -0.007 \\
Sausages & 0.006 & 0.086 & -0.002 \\
Softwood & -0.273 & 0.137 & 0.018 \\
Wine & 0.313 & 0.150 & 0.010 \\
Pooled-Quality & 0.027 & 0.061 & -0.001 \\
\hline
\end{tabular}

Table 28: Spatial correlation of materials prices.

Notes: The dependent variable is $p_{i j t}^{i n}$, and the independent variable is the (revenue-weighted) average of the $p_{i^{\prime} j t}^{i n}$ for the plants that are within a 250-mile radius of plant $i$ in industry $j$ and year $t$. Observations are given equal weight. See Table 6 for the real-revenue-weighted version of this table. 


\begin{tabular}{c|c|ccc|c|ccc}
\hline $\begin{array}{l}\text { Productivity } \\
\text { Measure }\end{array}$ & Total & Entry & Exit & $\begin{array}{l}\text { Net } \\
\text { Entry }\end{array}$ & Total & Entry & Exit & $\begin{array}{c}\text { Net } \\
\text { Entry }\end{array}$ \\
\hline$t f p r$ & -1.60 & -0.05 & 0.12 & 0.08 & 1.30 & 0.16 & 0.22 & 0.38 \\
$t f p q$ & -1.60 & -0.02 & 0.19 & 0.16 & 1.30 & 0.25 & 0.22 & 0.47 \\
$\phi$ & -1.60 & -0.05 & 0.17 & 0.12 & 1.30 & $0.17^{*}$ & 0.24 & 0.41 \\
\hline
\end{tabular}

Table 29: Aggregate productivity growth decompositions.

Notes: All values are given as percentages, over five-year horizons. In the first four columns, industries are assigned importance according to their total revenues. In the last four columns, industries are assigned importance according to the number of plants. Stars indicate that the value given in the cell is significantly different than the corresponding value that uses $t f p q$ as the measure of plant productivity. See Web Appendix C for details.

$$
\begin{aligned}
\Delta \overline{t f p}_{t}= & \sum_{i \in \mathcal{C}} \frac{1}{2}\left(\theta_{i, t-1}+\theta_{i, t}\right) \cdot \Delta t f p_{i t}+\sum_{i \in \mathcal{C}} \frac{1}{2}\left(t f p_{i, t}+t f p_{i, t-1}-\overline{t f p}_{t-1}-\overline{t f p}_{t}\right) \cdot \Delta \theta_{i t} \\
& +\underbrace{\sum_{i \in \mathcal{N}} \theta_{i t} \cdot\left(t f p_{i t}-\frac{1}{2} \overline{t f p}_{t-1}-\frac{1}{2} \overline{t f p_{t}}\right)-\sum_{i \in \mathcal{X}} \theta_{i, t-1} \cdot\left(t f p_{i, t-1}-\frac{1}{2} \overline{t f p}_{t-1}-\frac{1}{2} \overline{t f p}_{t}\right)}_{\text {Entry Effect }}
\end{aligned}
$$

The results of the alternate decomposition are given in Table 29. The magnitudes of the "Net Entry" effect are robust to the decomposition method.

\section{A.10 Correcting for Sample Selection in Decompositions of Indus- try Productivity Growth}

As mentioned in Section 2.2, plants in the benchmark sample tend to exit and enter less frequently, compared to plants from their corresponding industries. As a result, the productivity decompositions of Section 3.5 may underrepresent the role of entry and exit in generating aggregate productivity growth. In this subsection, I try to account for this sample selection problem.

Table 30 presents the aggregate productivity growth decompositions, corrected for the underrepresentation of entering and exiting plants in the benchmark sample. For each industry in my benchmark sample, I compute the corrected Entry (Exit) Effects by dividing by the ratio of the revenue-weighted fraction of entrants (exiting plants) in the overall sample to the revenue-weighted fraction of entrants (exiting plants) in the benchmark sample. The correction that I make will magnify the share of entrants/exiting plants to the extent that entrants/exiting plants are underrepresented in the benchmark sample. Specifically, the 
corrected Entry and Exit Effects are given by:

Entry Effect $_{F H K}=\frac{\operatorname{Pr}\{i \in \mathcal{N} \mid i \in \text { overall sample }\}}{\operatorname{Pr}\{i \in \mathcal{N} \mid i \in \text { benchmark sample }\}} \cdot \sum_{i \in \mathcal{N} \cap \text { benchmark }} \theta_{i, t-1} \cdot\left(t f p_{i t}-\overline{t f p}_{t-1}\right)$

Exit $\operatorname{Effect}_{F H K}=-\frac{\operatorname{Pr}\{i \in \mathcal{X} \mid i \in \text { overall sample }\}}{\operatorname{Pr}\{i \in \mathcal{X} \mid i \in \text { benchmark sample }\}} \cdot \sum_{i \in \mathcal{X} \text { กbenchmark }} \theta_{i, t-1} \cdot\left(t f p_{i, t-1}-\overline{t f p}_{t-1}\right)$

Entry Effect $_{G R}=\frac{\operatorname{Pr}\{i \in \mathcal{N} \mid i \in \text { overall sample }\}}{\operatorname{Pr}\{i \in \mathcal{N} \mid i \in \text { benchmark sample }\}} \cdot \sum_{i \in \mathcal{N} \text { nbenchmark }} \theta_{i t} \cdot\left(t f p_{i t}-\frac{1}{2} \overline{t f p}_{t-1}-\frac{1}{2} \overline{t f p}_{t}\right)$

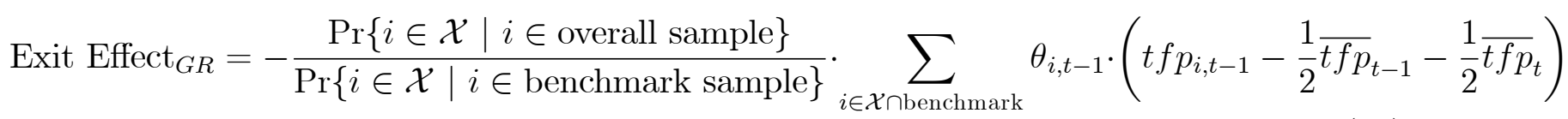

In Equations 36-39, FHK denotes the decomposition method of Foster, Haltiwanger, and Krizan (2001), while $G R$ denotes the decomposition method of Griliches and Regev (1995).

As in Table 8, I average over the industries in the benchmark sample to arrive at the aggregate Entry Effect, Exit Effect, and Net Entry Effect. The Net Entry Effect is less than 0.1 percentage points larger after correcting for the underrepresentation of entering and exiting plants in the benchmark sample. As in Table 8, the only statistically significant difference among the three productivity measures is that the role of entry, which is lager when $t f p q$, instead of $\phi$, is used as the productivity measure.

\section{A.11 Within-Supplier Price Deviations and Shipment Timing}

Some of the cross-buyer, within-supplier variation in input prices is potentially due to differences in the timing of shipments. I run two regressions to explore the within-supplier variation in input prices. In the first regression, the dependent variable is the logarithm of the difference between the shipment price and the supplier's average price ${ }^{50}$ the independent variables are indicator variables for the quarter of the shipment. In the second regression, I average the left- and right-hand side variables from the first regression. In particular, I

\footnotetext{
${ }^{50}$ Note the dependent variable is not quite the same as $\psi_{\text {hit }}$, as this latter variable combines all of the shipments made by $h$ to $i$ in year $t$.
} 


\begin{tabular}{cl|c|ccc|ccc}
\hline $\begin{array}{c}\text { Productivity } \\
\text { Measure }\end{array}$ & Weight & \multirow{2}{*}{ Total } & Entry & Exit & $\begin{array}{c}\text { Net } \\
\text { Entry }\end{array}$ & Entry & Exit & $\begin{array}{c}\text { Net } \\
\text { Entry }\end{array}$ \\
\hline$t f p r$ & Real Revenues & -1.60 & -0.06 & 0.11 & 0.04 & -0.06 & 0.17 & 0.11 \\
$t f p q$ & Real Revenues & -1.60 & -0.08 & 0.20 & 0.12 & -0.07 & 0.26 & 0.19 \\
$\phi$ & Real Revenues & -1.60 & -0.12 & 0.17 & 0.05 & -0.11 & 0.23 & 0.12 \\
$t f p r$ & \# of Plants & 1.30 & 0.30 & 0.17 & 0.47 & 0.20 & 0.28 & 0.49 \\
$t f p q$ & \# of Plants & 1.30 & 0.40 & 0.15 & 0.54 & 0.30 & 0.26 & 0.56 \\
$\phi$ & \# of Plants & 1.30 & $0.27^{*}$ & 0.18 & 0.45 & $0.18^{*}$ & 0.29 & 0.47 \\
\hline Decomposition Method & \multicolumn{5}{|c}{ Foster et. al } & Griliches and Regev \\
\hline
\end{tabular}

Table 30: Aggregate productivity growth decompositions.

Notes: See Equations 36-39. All values are percentages, over five-year intervals. When tfpr or $\phi$ is the productivity measure, stars indicate that the value given in the cell is significantly different than the corresponding value that uses $t f p q$ as the measure of plant productivity. See Web Appendix C for a detailed description of the bootstrapping procedure.

\begin{tabular}{lccc}
\hline Sample & Concrete & Boxes & Pooled \\
\hline Quarter 2 & 0.030 & -0.014 & -0.011 \\
& $(0.019)$ & $(0.038)$ & $(0.035)$ \\
Quarter 3 & 0.031 & 0.019 & 0.019 \\
& $(0.036)$ & $(0.028)$ & $(0.026)$ \\
Quarter 4 & 0.033 & 0.041 & 0.040 \\
& $(0.030)$ & $(0.024)$ & $(0.023)$ \\
Constant & -0.150 & 0.003 & -0.142 \\
& $(0.020)$ & $(0.020)$ & $(0.019)$ \\
Adjusted $R^{2}$ & 0.005 & 0.008 & 0.029 \\
$N$ & 520 & 1375 & 1895 \\
\hline
\end{tabular}

Table 31: Regression of shipment price (relative to the average for the supplier), against indicator variables of the quarter of the shipment.

Notes: All observations are weighed by the value of the shipment.

regress $\psi_{i t}$ against the fraction of shipment-value received by plant $i$ in quarter 2, in quarter 3 , and in quarter 4. The results of these regressions are given in Tables 31 and 32. For concrete, within-supplier deviations are smaller (though not significantly so) for shipments made in the first quarter. Overall, shipment timing explains only a small fraction of the dispersion in materials prices

\section{A.12 Figure 1, for Different Subsamples}

Figure 1 decomposes the price distribution of Commodity Flow Survey cement and paper shipments into two separate components. In the figure, cement shipments from 1992, paper shipments from 1992, and paper shipments from 1997 are pooled together. Figure 2 reproduces the decomposition of Figure 1, separately for each of these three subsamples. 

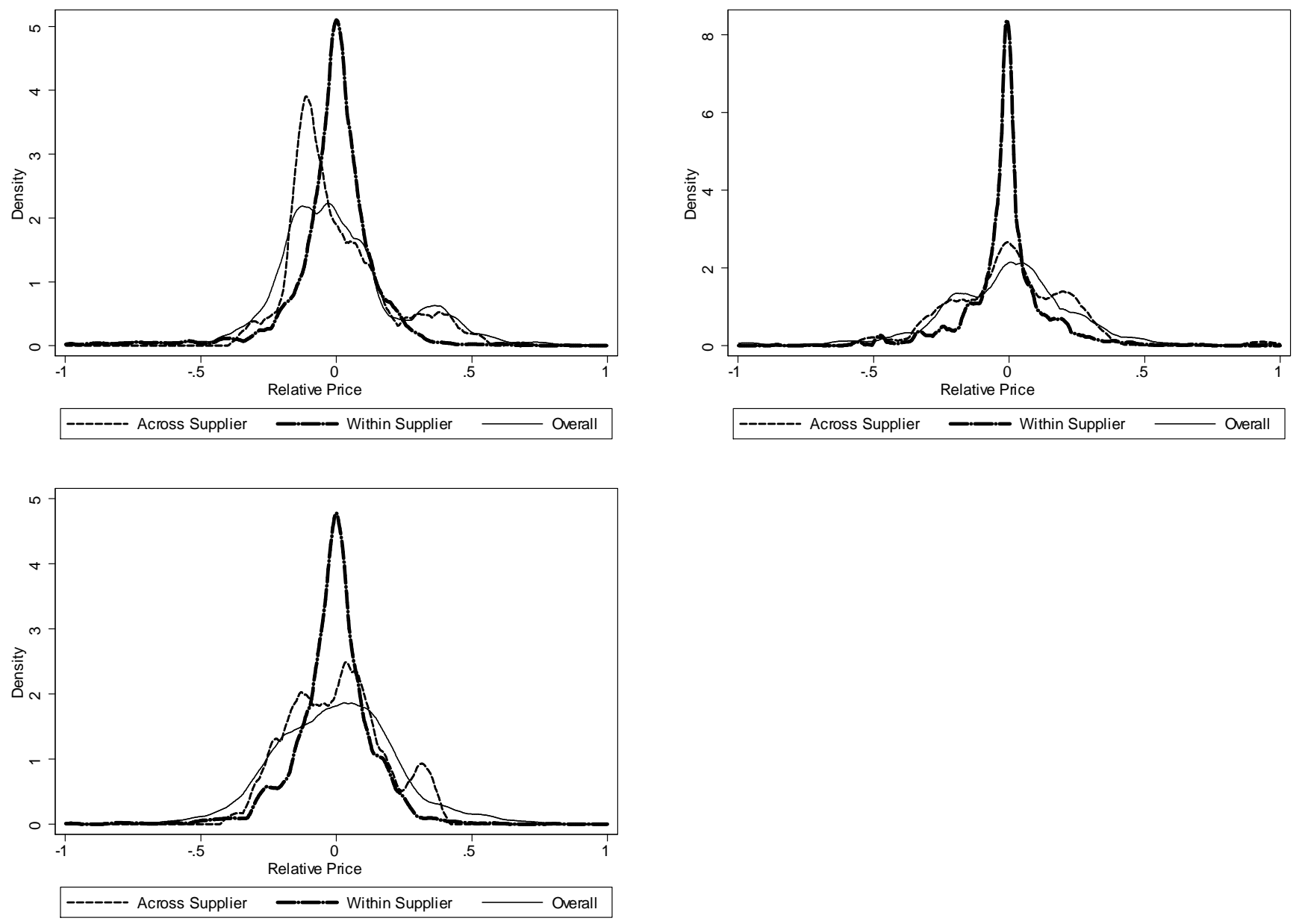

Figure 2: Value-weighted price distributions.

Notes: The sample includes all shipments sent by the cement and paperboard manufacturers that comprise the sample of the regressions defined by Equation 23. The top-left panel includes the sample of paperboard manufacturers, from 1992; the top-right panel includes the sample of cement manufacturers, from 1992; and, the bottom-left panel includes the sample of paperboard manufacturers, from 1997. 


\begin{tabular}{lccc}
\hline Sample & Concrete & Boxes & Pooled \\
\hline Quarter 2 & 0.245 & -0.033 & 0.002 \\
& $(0.215)$ & $(0.058)$ & $(0.058)$ \\
Quarter 3 & 0.114 & 0.011 & 0.020 \\
& $(0.228)$ & $(0.057)$ & $(0.059)$ \\
Quarter 4 & 0.232 & 0.031 & 0.058 \\
& $(0.202)$ & $(0.045)$ & $(0.048)$ \\
Constant & -0.331 & 0.000 & -0.200 \\
& $(0.193)$ & $(0.029)$ & $(0.073)$ \\
Adjusted $R^{2}$ & 0.072 & 0.012 & 0.080 \\
$N$ & 131 & 190 & 321 \\
\hline
\end{tabular}

Table 32: Regression of $\psi_{i t}$ against the fraction of shipment value that $i$ receives in quarter 2,3 , and 4 .

Notes: Observations are weighed by the revenues of plant $i$.

The main qualitative results of Figure 1 abide for each of the three subsamples. The within-supplier price distribution is less disperse, compared to the across-supplier distribution. The distributions are (roughly) unimodal, with the mean and the mode close to one another.

Of the two industries, the price distributions for paper are more disperse. For the two paper subsamples, the price distributions are very similar across the two years.

\section{A.13 Including Local Prices in the Regression Defined by Equa- tion 23}

One concern, regarding the regression corresponding to Equation 23 is that division fixed effects may not sufficiently control for the geographic forces that generate variation in $p_{i t}^{i n}$. Unfortunately, since there are so few observations in the sample of corrugated box and concrete manufacturers, I cannot include fixed effects of greater geographic detail. Instead, I include on the right-hand side of Equation 23- the average materials price paid by plants that are close to plant $i$. In particular, I define $\bar{p}_{i t}^{i n, l o c a l}$ as the logarithm of the average (value-weighted) price paid by all of the establishments, other than $i$, that are located less than 50 miles from plant $i$. Materials prices are spatially correlated for concrete, but not for boxes (i.e., $p_{i t}^{i n}$ is correlated to $\bar{p}_{i t}^{i n, l o c a l}$ only for the subsample of concrete manufacturers), consistent with the results of Section 3.3.

Regressions of plants' materials prices on suppliers' marginal costs are given in Table 33. The estimated coefficient corresponding to $\bar{p}_{i t}^{i n, l o c a l}$ is not significantly greater than 0 , and tends to be somewhat larger for the subsample of ready-mix concrete manufacturers. Im- 


\begin{tabular}{lcccccccccc}
\hline Sample & \multicolumn{3}{c}{ Boxes } & \multicolumn{3}{c}{ Concrete } & \multicolumn{3}{c}{ Pooled } \\
\hline$\overline{t f p q}_{i t}$ & $-0.267^{*}$ & $-0.255^{*}$ & $-0.230^{*}$ & $-0.195^{*}$ & -0.211 & -0.138 & $-0.253^{*}$ & $-0.243^{*}$ & $-0.211^{*}$ \\
& $(0.059)$ & $(0.058)$ & $(0.056)$ & $(0.092)$ & $(0.112)$ & $(0.106)$ & $(0.050)$ & $(0.048)$ & $(0.047)$ \\
$\psi_{i t}$ & & & $0.342^{*}$ & & & $0.698^{*}$ & & & $0.407^{*}$ \\
& & & $(0.112)$ & & & $(0.163)$ & & & $(0.118)$ \\
$\bar{p}_{i t}$ in local & 0.010 & 0.019 & 0.022 & 0.095 & -0.010 & 0.064 & 0.005 & 0.008 & 0.011 \\
$N$ & $(0.029)$ & $(0.029)$ & $(0.029)$ & $(0.088)$ & $(0.100)$ & $(0.082)$ & $(0.020)$ & $(0.019)$ & $(0.020)$ \\
Adjusted $R^{2}$ & 190 & 190 & 321 & 131 & 131 & 131 & 321 & 321 & 321 \\
Division F.E.? & 0.125 & 0.130 & 0.222 & 0.050 & 0.083 & 0.511 & 0.105 & 0.115 & 0.262 \\
\hline
\end{tabular}

Table 33: Regression results.

Notes: This table presents the coefficient estimates and robust standard errors, from the regressions defined by Equation 23, with the addition of $\bar{p}_{i t}^{i n, l o c a l}$ as an explanatory variable. The dependent variable in these regressions is $\tilde{p}_{i t}^{i n, C F S}$. Stars indicate significance at the $5 \%$ level.

portantly, the coefficient estimates of the $\overline{t f p q}_{i t}$ and $\psi_{i t}$ terms are unchanged after including $\bar{p}_{i t}^{i n, l o c a l}$ as an explanatory variable.

\section{B Construction of the Sample}

\section{B.1 Benchmark Sample}

The benchmark sample consists of 10 industries (collections of 7-digit products) for which both inputs and outputs display minimal levels of quality differentiation. The construction of the sample consists of plants for which the following five conditions hold. First, I discard any plants that have missing data on labor inputs, capital stocks, electricity bills, or materials bills. Second, I discard any plants that do not fill out either the Census of Manufacturers Materials Supplement (containing information on purchases of intermediate inputs) or the Census of Manufacturers Productivity Supplement (containing information on products produced). Third, I throw out plants that have imputed values for quantities of materials purchased or products produced. ${ }^{51}$ Fourth, I require that the plants in the

\footnotetext{
${ }^{51}$ White, Reiter, and Petrin (2012) argue that, because of survey nonresponse, on average, $40 \%$ of the non-administrative record plants in the Census of Manufacturers have imputed data. Moreover, because the Census uses industry averages to impute missing values for shipments, materials purchases, or other variables, the imputation method causes a downward bias in estimated within-industry productivity dispersions. The imputation method also biases the measured relationships among plant-level characteristics. With this in mind, I have chosen to exclude all plants with imputed data on the quantities of materials purchases or goods shipped. (Unfortunately, imputed-data flags for other variables - employment, electricity purchases, etc...- exist only beginning in 2002. However, using data from 2002, I have checked that there are very few observations with a) non-imputed quantities of materials/output and b) imputed values for other relevant variables. For 2002, I have also checked that the difference - between the three productivity measures - is robust to the inclusion/exclusion of observations that have imputed values for the "other" variables.) Then,
} 
benchmark sample earn at least half of their revenues from one of the 10 main industries. Fifth, I discard any plant that has an output price (defined by $p^{\text {out }}$, as in Equation 2), an input price (defined by $p^{i n}$, as in Equation 3 or 5 ), or a quantity total factor productivity (defined by $t f p q$, as in Equation 6) that is more than 3 units away than the average for that industry-year.

Industries are defined as the collection of 7-digit products in the following manner.

Coffee consists of two 7-digit products, whole bean coffee (2095111) and ground coffee (2095115). The units of output are thousands of pounds.

Ready-mix concrete consists of the single 7-digit product (3273000). In 1972 and 1977 some ready-concrete plants were producing a product with a code of 3273011 . The units of output are thousands of cubic yards. Production data do not exist for 1997; materials data do not exist for 1992 or 1997. Because of this, for the analysis in Section 3, the sample period for ready mix concrete is 1972-1987. The sample period for the analysis of Section 4, in which I use the Commodity Flow Survey but not the Census of Manufacturers' materials data, is 1992. In addition to the five criteria listed in the first paragraph of this subsection, I require ready-mix concrete plants to have positive purchases of both cement and sand/gravel.

White wheat flour is the combination of the 10 7-digit products: white flour, shipped for export (2041105 and 2041107); bakers' and institutional white bread-type flours (2041111 and 2041113); bakers' and institutional soft wheat flour (2041115 and 2041117); family white flour, other than self-rising (2041121 and 2041123); self-rising family white flour (2044126); and flour shipped to blenders or other processors (2041128 and 2041129). The units of white wheat flour are 50-pound sacks.

Gasoline is comprised of the following three 7-digit products: motor gasoline (2911131), distillate fuel oil (2911412), and No. 4 type light fuel oil (2911414). The units of output are thousands of barrels.

Bulk milk is the combination of fluid whole milk, bulk sales (2026112) and fluid skim milk, bulk sales (2026115). The units of bulk milk are thousands of pounds.

Packaged milk consists of the following three 7-digit products: fluid whole milk (2026212), low fat milk (202623), and skim milk (2026225). The units of output are thousands of quarts.

Sugar consists of the single 7-digit product, raw cane sugar (2061011). The units of output are short tons.

Yarn is comprised of the two 7-digit products, spun gray (2281110) and yarn, spun and finished in the same establishment (2281187). The units of output are thousands of

at least for my selected sample, I will be able to accurately measure within-industry dispersions of prices and productivities. 
pounds.

Corrugated boxes is a combination of nine 7-digit products, with products being classified by their end use. These end uses are containers of food and beverages (2653012); carry-out boxes for retail food (2653014); containers of paper and allied products (2653013); containers of glass, clay, and stone products (2653015); containers of metal products, machinery, equipment, and supplies (2653016); containers of electrical machinery, equipment, supplies, and appliances (2653018); containers of chemicals and drugs, including paints, varnishes, cosmetics, and soaps (2653021); containers of lumber and wood products, including furniture (2653022); all other end uses not specified (2653030). From 1972 to 1987, the units of output for corrugated boxes were thousands of pounds. From 1992 on, the units of output for corrugated boxes have been thousands of square feet.

Measuring corrugated boxes in terms of area, instead of mass, is somewhat problematic. Boxes' densities depend on their final use. In particular, the densities of boxes are lower for those that are used as containers of food, beverages, paper and allied products, glass, clay, stone, or metal, while the densities are higher for boxes that are used as containers of machinery, electronics, chemicals, lumber, and other products. Since the total cost of producing corrugated boxes seems to be more closely related to the mass - instead of surface area - of the amount produced, measured quantity total factor productivity for low density box manufacturers began to exceed, in 1992, the measured quantity total factor productivity of high density boxes.

To mitigate the impact of this measurement problem, I de-meaned, according to Equation 9, plant-level statistics separately for the high-density (those plants that produced output with a product code between 2653016 and 2653030) and low-density (those plants that produced output with a product code between 2653012 and 2653015) box manufacturers. ${ }^{52}$

In Table 34, I provide some descriptive statistics of the benchmark sample. The average $\log$ employment for plants is 3.93 (i.e., roughly $51 \approx e^{3.93}$ employees work in the average plant.) Plants that produce ready-mix concrete are one-third the size of the average benchmark-sample plant, while plants engaged in gasoline production employ approximately $6.1\left(\approx e^{5.74-3.93}\right)$ times as many workers as the average plant.

Compared to the universe of plants that are in the same 4-digit SIC industry, the plants in the benchmark sample employ $5.0\left(\approx e^{4.74-3.13}\right)$ times as many employees and have revenues that are $4.2\left(\approx e^{9.12-7.68}\right)$ times larger. The difference is due to the Census Bureau's survey methodology: the largest plants tend to receive the survey questionnaires

\footnotetext{
${ }^{52}$ Dropping the "Boxes, Year $\geq 1992$ " subsample does not change any of the results from Section 3. I find it worth the trouble to keep the "Boxes, Year $\geq 1992$ " subsample, since corrugated box manufacturers purchase one of their main inputs-namely, paperboard-from the manufacturing sector, and thus can be included in the analysis of Section 4.
} 


\begin{tabular}{lccccccc}
\hline & \multicolumn{2}{c}{ Employment } & \multicolumn{2}{c}{ Total Value of Shipments } & \multicolumn{2}{c}{$N$} & \multicolumn{2}{c}{ Main } \\
Sample & Benchmark & Main Ind. & Benchmark & Main Ind. & Benchmark & Main Ind. & Ind. \\
\hline Boxes, Yr._'87 & 5.399 & 3.998 & 9.426 & 8.404 & 1820 & 7742 & 2653 \\
Boxes, Yr._'92 & 5.559 & 3.998 & 9.799 & 8.404 & 646 & 7742 & 2653 \\
Coffee & 4.906 & 3.484 & 9.920 & 8.736 & 300 & 874 & 2095 \\
Concrete & 3.547 & 2.350 & 7.682 & 6.827 & 3708 & 20,956 & 3273 \\
Flour & 4.763 & 3.010 & 9.854 & 7.942 & 503 & 2073 & 2041 \\
Gasoline & 6.554 & 4.867 & 12.977 & 11.157 & 692 & 1706 & 2911 \\
Milk, Bulk & 3.950 & 3.441 & 9.082 & 8.023 & 127 & 7661 & 2026 \\
Milk, Packaged & 5.119 & 3.441 & 9.465 & 8.023 & 2099 & 7661 & 2026 \\
Sugar & 5.708 & 4.901 & 10.000 & 9.301 & 177 & 301 & 2061 \\
Yarn & 5.942 & 4.749 & 9.508 & 8.645 & 431 & 2233 & 2281 \\
Pooled & 4.740 & 3.128 & 9.119 & 7.689 & 10,503 & 43,546 & \\
\hline
\end{tabular}

Table 34: Descriptive statistics for the benchmark sample, and for the 4-digit SIC of which each product is a member.

Notes: Variables are stated in logs. The final column refers to the 4-digit SIC of which the product is a member.

on the products they produce or the materials they consume.

For a particular intermediate input to be included in the analysis, expenditures of the material input must make up at least $6 \%$ of total materials expenditures for that product group. As the cutoff expenditure share decreases, additional intermediate inputs are included in the analysis. Setting the cutoff too low results in the inclusion of intermediate inputs that are purchased only by a few plants, hindering cross-plant comparisons of materials prices. Setting the cutoff too high means that important components of plants' materials prices are ignored. The $6 \%$ cutoff seems like a good compromise between these two considerations.

In some instances, I combine groups of similar 6-digit products to form a given "material input." 53 For example, I combine material 131111 (domestic crude petroleum) and 131112 (foreign crude petroleum). The presumption when deciding to combine two materials is that the manufacturer is indifferent between the two 6-digit products. The way in which I combined these 6-digit products is given below.

Green coffee beans (017921) are the sole material input used in the production of ground/whole bean coffee.

In the production of ready-mix concrete, the two materials are cement (which was coded as 324101 in 1982 and 1992 and 324102 in other years) and sand/gravel aggregate (144201).

For white wheat flour, the sole material input is wheat (011111).

In the production of gasoline, I have combined foreign and domestic crude petroleum

\footnotetext{
${ }^{53}$ For 1992 and 1997, a description of the 6-digit material codes can be found by downloading MC92F7.dbf from the following Census web page: ftp://ftp2.census.gov/econ1992/MC92/.
} 
into one material input.

For milk (either bulk or packaged), the sole material input is unpasteurized whole milk (024111).

In the production of raw cane sugar, the sole material input is sugar cane (013321).

In the production of yarn, the two materials are raw cotton fibers (013101) and a combination of polyester staple and tow (282425) and acrylic staple and tow (282426).

Finally, in 1992-1997, the sole material input used in the production of corrugated boxes is coded 260003 ("Paper and Paperboard"). In 1987, the material input "Paper/Paperboard" is the combination of 262104 ("Paper, Cellulosic Wadding") and 262108 ("Paper"). Earlier than this, "Paper/Paperboard" is the combination of materials 262102, 262103 , and 262105.

\section{B.2 Quality Variation Sample}

Industries are defined as the collection of 7-digit products in the following manner:

Pickles are a combination of four products: dill pickles (2035211), sour pickles (2035213), sweet pickles (2035215), and refrigerated pickles (2035219). The units of output are thousands of gallons.

Sausages are a combination of six products: fresh sausage (2011711 and 2013711); dry or semi-dry sausages (2011717 and 2013717); and frankfurters (2011721 and 2013721). The units of output are thousands of pounds.

Softwood cut stock is a combination of two product groups: furniture cut stock (2421711) and industrial cut stock (2421751). The units of output are thousands of board feet.

Wine is a combination of the following three products: white grape wine (2084012), red grape wine (2084014), and rosé grape wine (2084016). The units of output are thousands of gallons.

As with the benchmark sample, materials that make up more than $6 \%$ of materials expenditures are included as "priced" materials. A summary of the characteristics of the Quality Variation sample are given in Table 35.

\section{Details of the Bootstrapping Exercises}

The purpose of this section is to describe, and give the results of, the four bootstrapping exercises that are employed in Sections 3 and 4. The four bootstrapping exercises are used to determine a) whether the correlations among certain plant-level statistics are significantly different from $0, \mathrm{~b}$ ) whether the dispersion of $t f p q$ is different from that of $\phi$ or $t f p r, c$ ) 


\begin{tabular}{|c|c|c|c|}
\hline Sample & Units of Output & Material Inputs & $N$ \\
\hline Pickles & $\begin{array}{l}1000 \\
\text { Gallons }\end{array}$ & $\begin{array}{l}\text { Cucumbers }(43 \%) \\
\text { Glass Containers }(28 \%)\end{array}$ & 145 \\
\hline Sausages & $\begin{array}{c}1000 \\
\text { Pounds }\end{array}$ & $\begin{array}{l}\text { Fresh and Frozen Pork }(34 \%) \\
\text { Fresh and Frozen Beef }(30 \%) \\
\text { Meat, Unknown Species }(13 \%)\end{array}$ & 621 \\
\hline $\begin{array}{l}\text { Softwood } \\
\text { Cut Stock }\end{array}$ & $\begin{array}{c}1000 \\
\text { Board Feet }\end{array}$ & $\begin{array}{l}\text { Softwood Dressed Lumber }(75 \%) \\
\text { Softwood Logs }(8 \%) \\
\text { Hardwood Dressed Lumber }(8 \%)\end{array}$ & 160 \\
\hline Wine & $\begin{array}{l}1000 \\
\text { Gallons }\end{array}$ & $\begin{array}{l}\text { Fresh Grapes }(41 \%) \\
\text { Purchased Wines }(23 \%) \\
\text { Glass Containers }(19 \%)\end{array}$ & 330 \\
\hline Pooled & - & - & 1256 \\
\hline
\end{tabular}

Table 35: Description of the four industries comprising the Quality Variation sample. The Material Inputs column gives the inputs that represent greater than $6 \%$ of the average plants' total material purchases. The percentages that appear in the Material Inputs column are the fraction of materials expenditures that go to each particular material input.

whether the Entry/Exit/Net Entry Effects (as in Equations 16 and 35) are significantly different when $t f p q$ is used instead of $\phi$ or $t f p r$, and d) whether the declines in dispersion that are reported in Table 11 are significantly more than would be expected by simply adding independent variables. Below, I explain how each of the bootstrapping exercises is performed, and give the resulting confidence intervals.

To determine whether specific correlations among plant-level statistics are different from 0, I take 1000 bootstrapped samples, from the benchmark sample of 10,503 plant-year observations (or 1256 observations in the case of the Quality Variation sample). In each bootstrapped sample, the number of plants taken from each industry-year is the same as in the benchmark sample. After sampling, I de-mean, as in Equation 9, and then compute the weighted and unweighted correlations. The $95 \%$ confidence intervals are provided in Tables 36 , and $37 .^{54}$

I follow a similar procedure to determine whether $t f p q$ is significantly more disperse than tfpr or $\phi$ : For each (out of 1000) bootstrapped sample, I de-mean plant-level statistics, as in Equation 9, and then compute dispersions (the standard deviations, the 90/10 ratios, and the $75 / 25$ ratios) of $t f p q, t f p r$, and $\phi$. I then take the ratio of the dispersion of $t f p q$ and the dispersion of either $t$ fpr or $\phi$. The $95 \%$ confidence intervals are provided in Table 38. In most cases, the left endpoint of the confidence interval is greater than 1 , meaning that $t f p q$ is significantly more disperse than both $t p f r$ and $\phi$. For the benchmark, pooled sample,

\footnotetext{
${ }^{54}$ Throughout this section, the confidence intervals correspond to the revenue-weighted calculations. Confidence intervals corresponding to the unweighted calculations are available upon request.
} 


\begin{tabular}{lccccccc}
\hline \multicolumn{1}{c}{ Sample } & $p^{\text {in }}, t f p q$ & $p^{\text {in }}, \phi$ & $p^{\text {in }}, p^{\text {out }}$ & $p^{\text {in }}, t f p r$ & $\phi, t f p q$ & $t f p q, t f p r$ & $t f p q, p^{\text {out }}$ \\
\hline Boxes, Yr. $\leq^{\prime} 87$ & $-0.36,-0.21$ & $0.14,0.31$ & $0.21,0.35$ & $-0.10,0.02$ & $0.83,0.90$ & $0.37,0.48$ & $-0.83,-0.76$ \\
Boxes, Yr. ${ }^{\prime} 92$ & $-0.43,-0.27$ & $0.00,0.18$ & $0.20,0.37$ & $-0.16,-0.01$ & $0.88,0.92$ & $0.03,0.20$ & $-0.90,-0.85$ \\
Coffee & $-0.69,-0.20$ & $-0.20,0.29$ & $0.10,0.57$ & $-0.48,0.16$ & $0.77,0.92$ & $0.38,0.74$ & $-0.73,-0.41$ \\
Concrete & $-0.36,-0.26$ & $0.07,0.17$ & $0.23,0.33$ & $-0.18,-0.08$ & $0.89,0.92$ & $0.71,0.77$ & $-0.52,-0.43$ \\
Flour & $-0.48,-0.31$ & $0.34,0.57$ & $0.18,0.43$ & $-0.18,0.15$ & $0.54,0.72$ & $0.00,0.27$ & $-0.78,-0.66$ \\
Gasoline & $-0.48,-0.31$ & $0.02,0.26$ & $0.06,0.26$ & $-0.40,-0.21$ & $0.82,0.89$ & $0.77,0.87$ & $-0.48,-0.27$ \\
Milk, Bulk & $-0.68,-0.13$ & $-0.44,0.14$ & $0.06,0.70$ & $-0.25,0.08$ & $0.93,0.98$ & $0.26,0.67$ & $-0.89,-0.56$ \\
Milk, Packaged & $-0.33,-0.23$ & $-0.02,0.11$ & $0.17,0.28$ & $-0.17,-0.04$ & $0.93,0.95$ & $0.37,0.49$ & $-0.80,-0.69$ \\
Sugar & $-0.22,0.14$ & $0.32,0.61$ & $0.03,0.40$ & $-0.08,0.28$ & $0.78,0.92$ & $0.76,0.93$ & $-0.58,-0.32$ \\
Yarn & $-0.45,-0.17$ & $-0.05,0.40$ & $0.08,0.36$ & $-0.29,-0.05$ & $0.82,0.92$ & $0.36,0.61$ & $-0.84,-0.67$ \\
Pooled-Bench. & $-0.42,-0.31$ & $0.05,0.20$ & $0.18,0.28$ & $-0.30,-0.16$ & $0.85,0.89$ & $0.65,0.74$ & $-0.60,-0.50$ \\
\hline Pickles & $-0.41,0.05$ & $-0.14,0.35$ & $-0.13,0.31$ & $-0.35,0.11$ & $0.93,0.97$ & $0.29,0.60$ & $-0.84,-0.61$ \\
Sausages & $-0.33,-0.04$ & $0.12,0.39$ & $0.06,0.35$ & $-0.09,0.19$ & $0.87,0.92$ & $0.10,0.44$ & $-0.84,-0.73$ \\
Softwood & $-0.66,-0.23$ & $-0.32,0.19$ & $0.22,0.66$ & $-0.35,0.05$ & $0.87,0.94$ & $0.15,0.56$ & $-0.97,-0.89$ \\
Wine & $-0.47,-0.12$ & $0.08,0.50$ & $0.11,0.52$ & $-0.23,0.34$ & $0.71,0.86$ & $0.00,0.48$ & $-0.89,-0.69$ \\
Pooled-Quality & $-0.38,-0.17$ & $0.14,0.36$ & $0.16,0.41$ & $-0.14,0.19$ & $0.82,0.89$ & $0.16,0.42$ & $-0.86,-0.75$ \\
\hline
\end{tabular}

Table 36: Confidence intervals of correlations among plant-level characteristics.

\begin{tabular}{lcccc}
\hline \multicolumn{5}{l}{ Benchmark Sample: } \\
\hline \multicolumn{5}{c}{$p^{\text {in }}$} \\
\hline$p^{\text {out }}$ & $0.180,0.279$ & $t f p q$ & $\phi$ \\
$t f p q$ & $-0.424,-0.314$ & $-0.599,-0.504$ & & \\
$\phi$ & $0.054,0.200$ & $-0.518,-0.422$ & $0.852,0.890$ & \\
$t f p r$ & $-0.303,-0.163$ & $0.149,0.284$ & $0.652,0.736$ & $0.568,0.660$ \\
\hline Output Quality Variation Sample: & & \\
\hline \multicolumn{5}{c}{$p^{\text {in }}$} \\
\hline$p^{\text {out }}$ & $0.160,0.407$ & & $t f p q$ & \\
$t f p q$ & $-0.385,-0.166$ & $-0.858,-0.165$ & & \\
$\phi$ & $0.137,0.363$ & $-0.733,-0.560$ & $0.819,0.888$ & \\
$t f p r$ & $-0.143,0.180$ & $0.241,0.423$ & $0.157,0.418$ & $0.189,0.404$ \\
\hline
\end{tabular}

Table 37: Confidence intervals of correlations among plant-level characteristics. 


\begin{tabular}{|c|c|c|c|c|c|c|}
\hline \multirow[b]{2}{*}{ Sample } & \multicolumn{3}{|c|}{$\begin{array}{l}\text { Ratio of dispersion of } t f p q \\
\text { to dispersion of } \phi\end{array}$} & \multicolumn{3}{|c|}{$\begin{array}{l}\text { Ratio of dispersion of } t f p q \\
\text { to dispersion of } t f p r\end{array}$} \\
\hline & $90 / 10$ & $75 / 25$ & SD & $90 / 10$ & $75 / 25$ & SD \\
\hline Boxes, Yr. $\leq ' 87$ & $1.002,1.078$ & $0.972,1.058$ & $1.002,1.060$ & $1.573,1.757$ & $1.427,1.908$ & $1.654,2.098$ \\
\hline Boxes, Yr. $\geq 92$ & $1.022,1.146$ & $1.008,1.123$ & $1.022,1.117$ & $2.534,4.309$ & $2.517,3.853$ & $2.024,3.230$ \\
\hline Coffee & $8,1.783$ & 1.012 & $1.018,1.406$ & $94,2.182$ & $0.903,2.016$ & $0.947,1.590$ \\
\hline & 8 & 1.0 & 1.0 & 76 & 1.02 & 1.072 \\
\hline Flc & 0 & 1.0 & 0.927 , & 92 & 1.2 & 0.992 \\
\hline Gasolir & $6,1.170$ & 0.974 & 0.976 & $0.931,1.146$ & 0.911 & 0.980 \\
\hline Milk, & $970,1.401$ & $0.854,1.498$ & 0.970 & $0.977,6.031$ & $0.795,4.583$ & $1.166,3.287$ \\
\hline Milk, Packaged & $1.036,1.110$ & $1.009,1.113$ & $1.036,1.062$ & $1.485,2.072$ & $1.562,1.942$ & $1.375,1.863$ \\
\hline Sugar & $710,1.018$ & $0.689,1.233$ & 0.710 & $0.931,1.364$ & 0.834 & $1.030,1.275$ \\
\hline Yarn & $0.824,1.028$ & $0.770,1.027$ & $0.824,1.109$ & $1.220,2.101$ & $1.118,2.017$ & $1.341,2.239$ \\
\hline $\begin{array}{l}\text { Pooled: } \\
\text { Weighted }\end{array}$ & $1.002,1.168$ & $0.996,1.200$ & $1.002,1.104$ & $1.066,1.227$ & $0.984,1.281$ & $1.123,1.249$ \\
\hline $\begin{array}{l}\text { Pooled: } \\
\text { Unweighted }\end{array}$ & $1.056,1.091$ & $1.050,1.093$ & $1.028,1.050$ & $1.415,1.515$ & $1.474,1.600$ & $1.303,1.374$ \\
\hline
\end{tabular}

Table 38: Confidence intervals.

Notes: The confidence intervals are of a) the ratio of the dispersion of $t f p q$ to the dispersion of $t f p r$-given in the left three columns-and b) the ratio of the dispersion of $t f p q$ to the dispersion of $\phi$-given in the right three columns.

$t f p q$ is significantly more disperse than $\phi$, except when observations are revenue weighted and the interquartile range is the measure of dispersion.

Table 39 presents the confidence intervals, related to the Caves, Christensen, and Diewert (1982) robustness check of Web Appendix A.5. As in the benchmark calculations, $t f p q$ is significantly more disperse than $\phi$, except when observations are revenue weighted and the interquartile range is the measure of dispersion. Revenue productivity is less disperse than quantity productivity for two of the three measures of dispersion, in the weighted calculations, and one of the three measures of dispersion, when observations are assigned equal weights. Other differences are not statistically significant.

And again, I follow a similar procedure to determine whether the Entry/Exit/Net Entry Effects (as in Equations 16 and 35) are significantly different when $t f p q$ is used instead of $\phi$ or $t f p r$. Again, I take 1000 bootstrapped samples, where, in each bootstrapped sample, the number of plants taken from each industry-year is the same as in the benchmark sample. For each bootstrapped sample, I compute the Entry, Exit, and Net Entry Effects, by plugging in $t f p q, t f p r$, and $\phi$ into Equations 16 and 35. I then compute the difference, between the Entry/Exit/Net Entry Effects when $t f p q$ is used instead of $t$ fpr (or $\phi$ ).

Table 40 gives the resulting confidence intervals. In the first and the third rows, 0 lies within each and every confidence interval: The Entry/Exit/Net Entry Effects are not 


\begin{tabular}{lcccccc}
\hline & \multicolumn{3}{c}{$\begin{array}{c}\text { Ratio of dispersion of } t f p q \\
\text { to dispersion of } \phi\end{array}$} & \multicolumn{3}{c}{$\begin{array}{c}\text { Ratio of dispersion of } t f p q \\
\text { to dispersion of } t f p r\end{array}$} \\
\hline \multicolumn{1}{c}{ Sample } & $90 / 10$ & $75 / 25$ & SD & $90 / 10$ & $75 / 25$ & SD \\
\hline $\begin{array}{l}\text { Pooled: } \\
\text { Weighted }\end{array}$ & $1.024,1.156$ & $0.975,1.184$ & $1.007,1.083$ & $0.969,1.102$ & $0.932,1.105$ & $1.006,1.092$ \\
$\begin{array}{l}\text { Pooled: } \\
\text { Unweighted }\end{array}$ & $1.068,1.109$ & $1.054,1.106$ & $1.037,1.060$ & $1.107,1.172$ & $1.078,1.150$ & $1.122,1.173$ \\
\hline
\end{tabular}

Table 39: Confidence intervals.

Notes: The confidence intervals are of a) the ratio of the dispersion of $t f p q$ to the dispersion of $t f p r$-given in the left three columns-and b) the ratio of the dispersion of $t$ fpq to the dispersion of $\phi$-given in the right three columns.

\begin{tabular}{cc|ccc|ccc}
\hline \multirow{2}{*}{ Measure } & $\begin{array}{l}\text { Weight } \\
\text { Industries By: }\end{array}$ & Entry & Exit & Net Entry & Entry & Exit & \multirow{2}{*}{ Net Entry } \\
\hline$t f p r$ & Revenues & $-0.06,0.11$ & $-0.05,0.19$ & $-0.07,0.23$ & $-0.06,0.11$ & $-0.06,0.19$ & $-0.07,0.24$ \\
$\phi$ & Revenues & $-0.02,0.09$ & $-0.06,0.10$ & $-0.05,0.14$ & $-0.02,0.09$ & $-0.07,0.10$ & $-0.05,0.13$ \\
$t f p r$ & Plants & $-0.05,0.23$ & $-0.12,0.13$ & $-0.09,0.28$ & $-0.04,0.23$ & $-0.12,0.13$ & $-0.09,0.28$ \\
$\phi$ & Plants & $0.00,0.16$ & $-0.09,0.05$ & $-0.05,0.15$ & $0.01,0.15$ & $-0.10,0.06$ & $-0.04,0.15$ \\
\hline \multicolumn{2}{c|}{ Decomposition Method } & \multicolumn{2}{|c|}{ Foster, Haltiwanger, and Krizan } & \multicolumn{3}{c}{ Griliches and Regev } \\
\hline
\end{tabular}

Table 40: Confidence intervals.

Notes: The confidence intervals are of the difference, when $t f p q$, instead of $t f p r / \phi$, is used as the measure of plant productivity, of the Entry Effect, Exit Effect, and Net Entry Effect. These three effects are defined in Equations 16 and 35.

significantly different for revenue productivity versus quantity productivity. On the other hand, when industries are weighed by the number of plants, the Entry Effect is significantly greater when $t f p q$, instead of $\phi$, is used as the measure of productivity.

I follow a somewhat different procedure to determine whether the estimated dispersion declines, as reported in Table 11 are significantly more than would be expected by simply adding independent variables. I implement the following algorithm 1000 times:

From the sample of plant-year observations, I construct a new variable, $\mathcal{P}\left(\tilde{p}_{i t}^{i n, C F S}\right)$, which is constructed by randomly permuting $\tilde{p}_{i t}^{i n, C F S}$ among the observations from a given industry-year. I then regress $\mathcal{P}\left(\tilde{p}_{i t}^{i n, C F S}\right)$ against all the combinations of right-hand side variables of the regression given in Equation 23. Following these regressions, I compute the revenue-weighted standard deviations of the residuals. These residuals are stored, for each iteration.

The $95 \%$ confidence intervals are presented in Table 41 . The first three rows present the confidence intervals related to the specifications that exclude $\psi_{i t}$ as an explanatory variable. The final three rows give the confidence intervals related to the specifications that include $\psi_{i t}$. To make things concrete, consider the values given in the first row and penultimate column. 


\begin{tabular}{|c|c|c|c|c|c|}
\hline \multicolumn{2}{|c|}{$\begin{array}{l}\text { Include Division } \\
\text { Fixed Effects? }\end{array}$} & No & Yes & No & Yes \\
\hline \multicolumn{2}{|c|}{$\begin{array}{l}\text { Include } \\
\overline{t f p q}_{i t} ?\end{array}$} & No & No & Yes & Yes \\
\hline $\begin{array}{c}\text { Sample } \\
\text { Size }\end{array}$ & Sample & & & & \\
\hline 131 & Concrete & & $0.292,0.354$ & $0.342,0.359$ & $0.288,0.352$ \\
\hline 190 & Boxes & & $0.175,0.185$ & $0.184,0.187$ & $0.175,0.185$ \\
\hline 321 & Pooled & & $0.200,0.208$ & $0.206,0.209$ & $0.199,0.207$ \\
\hline 131 & Concrete & $0.333,0.359$ & $0.286,0.352$ & $0.327,0.359$ & $0.284,0.351$ \\
\hline 190 & Boxes & $0.184,0.187$ & $0.174,0.185$ & $0.182,0.187$ & $0.174,0.185$ \\
\hline 321 & Pooled & $0.206,0.209$ & $0.199,0.208$ & $0.205,0.209$ & $0.195,0.207$ \\
\hline
\end{tabular}

Table 41: Confidence intervals.

Notes: The first three rows present the confidence intervals related to the specifications that exclude $\psi_{i t}$ as an explanatory variable. The final three rows give the confidence intervals related to the specifications that include $\psi_{i t}$.

To construct these two values, I repeatedly regress random permutations of $\mathcal{P}\left(\tilde{p}_{i t}^{i n, C F S}\right)$ against $\overline{t f p q}_{i t}$, and then store the standard deviation of the residuals from each regression. The smaller value equals the 2.5-percentile standard deviation, and the larger value equals the 97.5-percentile standard deviation.

\section{Additional References}

White, T. Kirk, Jerome P. Reiter, and Amil Petrin (2012). "Plant-level Productivity and Imputation of Missing Data in U.S. Census Manufacturing Data." NBER Working Paper No. 17816. 